OPEN ACCESS

Edited by:

Tiago W. P. Mineo,

Federal University of Uberlandia, Brazil

Reviewed by:

Jillian M. Richmond,

University of Massachusetts Medical

School, United States

Onyeka Nwufoh,

University of Ibadan, Nigeria

*Correspondence:

Shumaila Naz

shumaila.naz@numspak.edu.pk

${ }^{t}$ These authors have contributed equally to this work

Specialty section:

This article was submitted to

Parasite Immunology,

a section of the journal

Frontiers in Immunology

Received: 17 September 2021 Accepted: 02 November 2021 Published: 01 December 2021

Citation:

Shehwana H, ljaz S, Fatima A, Walton S, Sheikh ZI, Haider W and Naz S (2021) Transcriptome

Analysis of Host Inflammatory

Responses to the Ectoparasitic Mite

Sarcoptes scabiei var. hominis.

Front. Immunol. 12:778840.

doi: 10.3389/fimmu.2021.778840

\section{Transcriptome Analysis of Host Inflammatory Responses to the Ectoparasitic Mite Sarcoptes scabiei var. hominis}

\author{
Huma Shehwana ${ }^{1 \dagger}$, Sadaf ljaz ${ }^{2 \dagger}$, Abeera Fatima ${ }^{2}$, Shelley Walton ${ }^{3}$, Zafar lqbal Sheikh ${ }^{4}$, \\ Waseem Haider ${ }^{5}$ and Shumaila Naz ${ }^{1 *}$ \\ 1 Department of Biological Sciences, National University of Medical Sciences, Rawalpindi, Pakistan, ${ }^{2}$ Research Centre for \\ Modelling \& Simulation, National University of Science and Technology, Islamabad, Pakistan, ${ }^{3}$ Inflammation and Healing \\ Research Cluster, School of Health and Sport Sciences, University of the Sunshine Coast, Maroochydore, QLD, Australia, \\ ${ }^{4}$ Department of Dermatology, Pak-Emirates Military Hospital, Rawalpindi, Pakistan, ${ }^{5}$ Department of Biosciences, COMSATS \\ University Islamabad, Islamabad, Pakistan
}

Scabies, a human skin infestation caused by the ectoparasitic mite Sarcoptes scabiei var. hominis, affects more than 200 million people globally. The prevailing knowledge of the disease process and host immune response mechanisms is limited. A better understanding of the host-parasite relationship is essential for the identification of novel vaccine and drug targets. Here we aimed to interrogate the transcriptomic profiles of miteinfested human skin biopsies with clinical manifestations of ordinary scabies subjects ("OS"; $n=05$ ) and subjects naive to scabies ("control"; $n=03$ ) using RNASeq data analysis. A combined clustering, network, and pathway mapping approach enabled us to identify key signaling events in the host immune and pro-inflammatory responses to $S$. scabiei infestation. The clustering patterns showed various differentially expressed genes including inflammatory responses and innate immunity genes (DEFB4A, IL-19, CXCL8, CSF3, SERPINB4, S100A7A, HRNR) and notably upregulation of the JAK-STAT pathway in scabies-infested samples. Mite-infested human skin biopsies (GSE178563) were compared with an ex-vivo porcine infested model (E-MTAB-6433) and human skin equivalents (GSE48459). Marked enrichment of immune response pathways (JAKSTAT signaling, IL-4 and IL-13 pathway, and Toll receptor cascade), chemokine ligands and receptors (CCL17, CCL18, CCL3L1, CCL3L3, CCR7), and cytokines (IL-13 and IL-20) were observed. Additionally, genes known for their role in psoriasis and atopic dermatitis were upregulated, e.g., IL-19. The detailed transcriptomic profile has provided an insight into molecular functions, biological processes, and immunological responses and increased our understanding about transcriptomic regulation of scabies in human.

Keywords: RNA-seq data analysis, Sarcoptes scabiei. var. hominis, inflammatory responses, scabies, differentially expressed genes, JAK-STAT pathways 


\section{INTRODUCTION}

Scabies is a common contagious human skin infestation caused by ectoparasite Sarcoptes scabiei var. hominis (S. scabiei var. hominis) $(1,2)$. World Health Organization (WHO) listed scabies as one of the top 50 epidemics worldwide $(3,4)$ with an infection rate as high as $50-80 \%$ in certain populations, and up to $10 \%$ of the global human population infected (5). Infestation by the mite almost always leads to the development of localized skin inflammation, itching, and burrow formation; rash and itch possibly being an indicator of host immune response with features of both type I and type IV hypersensitivity reactions (6).

The initial immune response towards the mite and its products, by different hosts, consists of keratinocytes, neutrophils, Langerhans cells, and macrophages $(7,8)$, which initiate an inflammatory and immune reaction (9). Granulocytes are engaged in boosting the immunity of the host against a variety of parasites by initiating immunomodulation and producing cytokines and chemokines, which direct the immune response. Upon recruitment to infection site/draining lymph nodes, eosinophils, mast cells, and basophils produce IL-4 and /or IL-13 (10). In a study reported by Walton et al. in 2008, skin biopsies taken from scabies patients having crusted lesions showed large numbers of lymphocytes, monocytes, macrophages, and eosinophils in the dermis, with increased levels of $\mathrm{IgE}$ in the blood samples. Similar findings have also been reported in the skin, upper airways, and lung cellular infiltrates present in chronic allergic inflammation (11).

The immune response to $S$. scabiei consistently shows increased levels of $\mathrm{CD} 4+$ or CD8+ $\mathrm{T}$ cells. CD4+ T cells mostly dominate the infiltrates of skin biopsy lesions in ordinary scabies, with a $4: 1$ ratio of $\mathrm{CD} 4+$ to $\mathrm{CD} 8+\mathrm{T}$ cells $(12$, 13). This is similar to studies of inflammatory cells in the biopsies of skin lesions from patients with atopic dermatitis, which demonstrate significantly greater number of infiltrating CD4+ lymphocytes compared with CD8+ subtypes (14). In comparison, the skin inflammatory response in patients with crusted scabies predominantly comprises CD8+T cells $(6,12)$.

Scabies mites are highly host-specific and commonly produce a temporary, self-limiting reaction in the non-preferred host (15). Previous animal studies of host immune response in scabies have used S. scabiei var. canis whole mite antigen extracts in rabbits and mice, but interpretation of these studies is mystified probably by a mismatched host-parasite system (16). However, various studies have consistently shown that the immune response of the host to ordinary scabies is a Th1 cell-mediated protective type and to the crusted variety of the scabies is a nonprotective Th2 allergic response $(6,17,18)$. In addition, Crusted Scabies (CS) patients have shown increased production of Th2 cytokines IL-4, IL-5, and IL-13 and decreased secretion of the Th1 cytokine IFN- $\gamma$ as compared to OS (19).

The prevailing knowledge of the disease processes and host immune response mechanisms is limited, and a better understanding of the host-parasite relationship is essential to develop a novel vaccine or a drug (20). mRNA profiling will provide new insights into the events/signaling mechanisms leading to the development of immune and pro-inflammatory responses in scabies. Recent gene expression findings using microarray in sheep scab, psoriasis, and atopic dermatitis indicate a direct relationship between gene expression and disease phenotype $(19,21)$.

The pattern of gene expressions is incredibly useful in understanding the various pathways involved in the immune response to scabies. Scabies, being an inflammatory allergic disease, shares similar clinical symptoms and immune and inflammatory responses to psoriasis, atopic dermatitis, and sheep scab (22). Further understanding of the pathways involved in immune responses to scabies might also be useful in understanding the immunogenic responses to other inflammatory allergic diseases. In this study, we have examined the transcriptomic profiles of skin RNA samples of scabies patients and healthy controls and identified the key signaling events in the host immune and pro-inflammatory responses to S. scabiei infestation. As we did not find any transcriptome profiling using human skin biopsies, we have performed comparative analysis on artificially infested porcine samples, i.e., E-MTAB-6433 (23) and human skin equivalents, i.e., GSE48459 (24), with our model to identify a robust gene signature.

\section{MATERIALS AND METHODS}

The workflow of the methodology to examine the transcriptomic profiles of skin RNA samples of scabies patients and healthy controls and to identify the key signaling events in the host immune to S. scabiei var. hominis infestation is given in Figure 1.

\section{Ethical Approval}

Ethical approval for collection of human skin biopsies was granted by the Chairman, Institutional Review Board, and Ethics Committee of the National University of Medical Sciences (NUMS), Rawalpindi, Pakistan, after compliance to the observations of the two reviewers, under letter No. NUMS/P (VC) - 17/R\&D/ORIC/IRB\&EC approved on November 9, 2017.

\section{Sample Collection}

Skin biopsies were collected from patients clinically diagnosed to have been suffering from scabies by visiting the Department of Dermatology in Pak-Emirates Military Hospital (PEMH), Rawalpindi, Pakistan, between January to March 2018. The skin biopsies were collected after obtaining written informed consent from a total of eight participants in two categories: ordinary scabies subjects ("OS"; $\mathrm{n}=05$ ) and individuals naive to scabies and allergy with no known exposure to scabies or allergy (control"; $\mathrm{n}=03$ ). Before biopsy, the skin was thoroughly cleaned and a small injection of a local anesthetic (Lignocaine Injection) to numb the skin was made. The $3 \mathrm{~mm}$ punch skin biopsies were collected from lesional sites of each patient. The cases of OS were confirmed by clinical observation and positive identification of mites and mite parts, collected from skin scrapings, under the microscope (1 mite or mite part/ scraping). The data about age, gender, locality, and duration of 


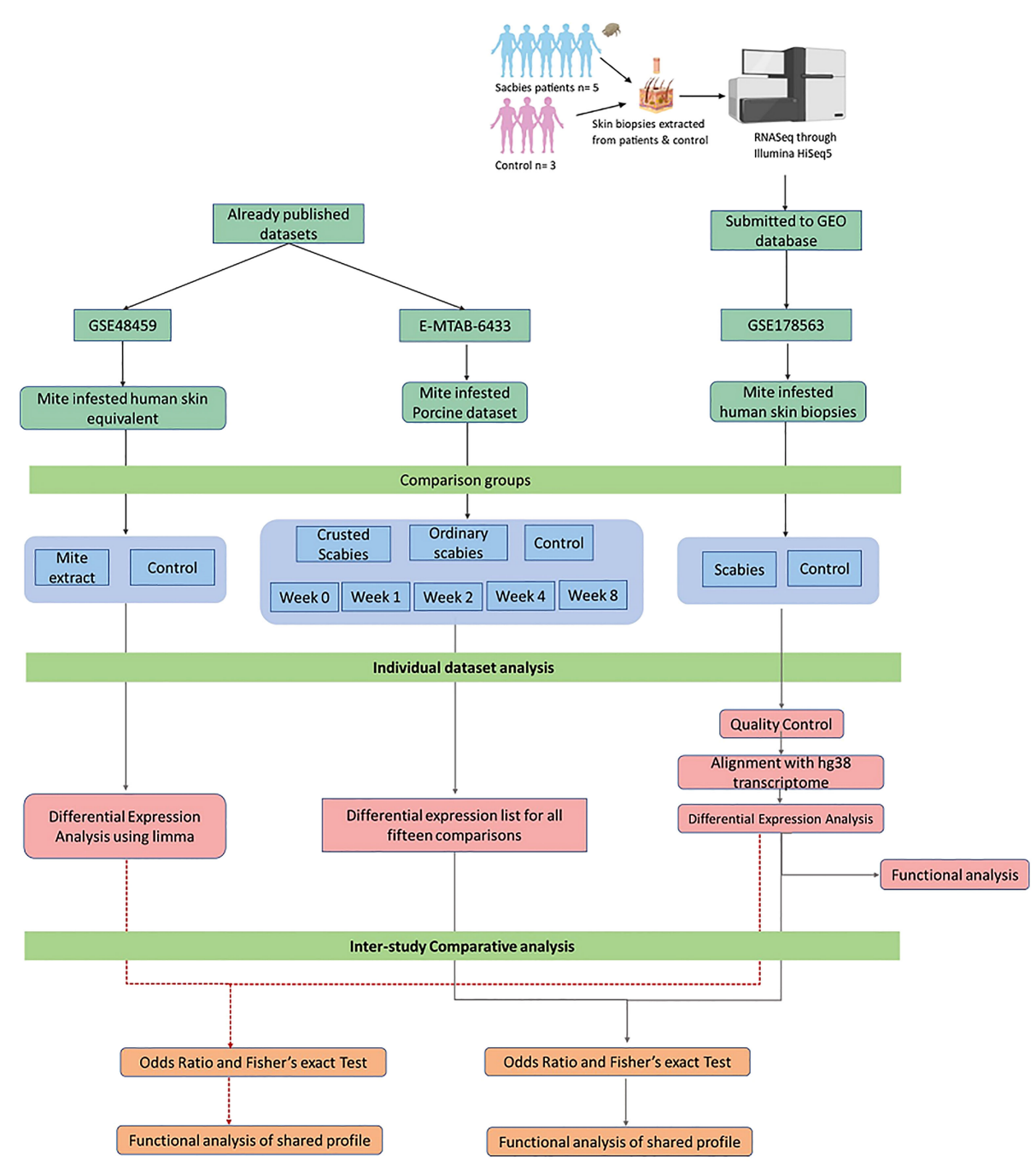

FIGURE 1 | Workflow of the project.

infestation was obtained by questionnaire and recorded. Skin biopsies were stored in RNAlater (Thermo Fisher Scientific, USA) at $-20^{\circ} \mathrm{C}$ till shipping on ambient temperatures to Novogene, China, for Next-Generation Sequencing (NGS).

\section{RNA Extraction, Library Preparation, and RNA Sequencing}

mRNA extraction of skin biopsies was performed by Novogene, Beijing (China). The preliminary Quality Control (QC) check of mRNA samples was done on agarose gel electrophoresis. The quantity and purity of the RNA samples were checked using a Qubit fluorometer, while Agilent 2100 was used to check the RNA integrity (RIN) of the samples. Library preparation and mRNA sequencing were performed as per the standard procedure. Sequencing was done on an Illumina HiSeq4000 instrument, generating 150 base-pair (bp) PE sequencing data.

\section{RNA-Seq Data Analysis}

Quality control of raw RNA-seq data was evaluated using FASTQC (http://www.bioinformatics.babraham.ac.uk/projects/ fastqc/). Paired-end reads were aligned to the human reference transcriptome (hg38) obtained from UCSC genome browser using Burrows-Wheeler Alignment (BWA-mem algorithm) (25). Transcript-specific count data of aligned samples were obtained using the HTSeq-count tool (26). Differential expression analysis between ordinary scabies and control samples was performed on raw count data by using the exact test from the edgeR 3.34 package (27).

\section{Pathway Enrichment Analysis and Gene Set Enrichment Analysis}

Genes exhibiting significant differences between both groups $(\mathrm{p}<0.05$ and $\log \mathrm{FC}>$ absolute 2$)$ were used for 
pathway enrichment analysis using Database for Annotation, Visualization, and Integrated Discovery (DAVID) online tool version $6.8(28,29)$. Upregulated and downregulated gene lists were separately queried using Gene Ontology (Biological Processes, Molecular Function) and Kyoto Encyclopedia of Genes and Genomes (KEGG) databases in DAVID online tool. Terms with FDR $(\mathrm{BH})<0.05$ were considered as significantly enriched functional classification and are represented in the form of plots.

In addition, gene set enrichment analysis was performed using GSEA software v. 4.1.0 (Broad Institute, MIT, Cambridge, MA, USA) (30). Raw gene count data were logtransformed, and genes with no or little variation $(\mathrm{SD}<0.25)$ were removed prior to GSEA analysis. GSEA software was run using MSIGDB Gene Ontology-Biological processes gene set database with the customized settings (1,000 iterations, gene set permutation, and 149 seed value). Significant terms in the enrichment map $(\mathrm{FDR}<0.1$ and $\mathrm{p}<0.005)$ were visualized using cystoscope software.

\section{Comparative Analysis With E-MTAB-6433}

For comparative analysis with E-MTAB-6433, time-series based differential gene expression lists for OS vs. C, CS vs. C, and CS vs. OS were retrieved from database (23). We obtained PorcineHuman orthologs gene lists from the ensemble Biomart database by using the $\mathrm{R}$ package biomaRt 3.13 (31). Differentially expressed gene lists from the porcine studies were merged with our human-infested skin biopsy dataset using ortholog lists (edgeR results; $\mathrm{p}<0.05$ ). Odds ratio and fishers exact test were used to find the association of human skin biopsy scabies dataset with each combination of time-series Pig dataset. Correlation analysis was performed using the stat_cor function (ggpubr package) in $\mathrm{R}$.

\section{Comparative Analysis With GSE48459}

We downloaded RNA normalized data of human skin equivalent gene expression data (GSE48459) from the GEO database (24). GSE48459 is based on Affymetrix Human Gene 1.0 ST Array. Probe to gene annotation was retrieved from Ensembl Biomart. Differential expression analysis was performed on live mites $v s$. control using the Limma package (32). To represent each gene with one probe, duplicate probes were removed by selecting a single probe with the smallest p-value. GSE48459 was merged with our human skin biopsies dataset using Ensembl gene IDs. Significantly differentially expressed profiles ( $\mathrm{p}$-value $<0.05)$ from both datasets, i.e., (GSE48459-live mites vs. untreated human skin equivalents), and human skin biopsies (scabies vs. nolesion) were compared using odds ratio and fisher's exact test. Correlation analysis was performed using the statcor function (ggpubr package).

\section{Graphs Visualization}

Venn diagrams were generated using vennerable package. Graphs were plotted using ggplot2 package. All analysis was performed in $\mathrm{R}$.

\section{RESULTS}

In the present study, we have collected skin biopsies of five patients including four males and one female. The skin biopsy was taken from confirmed scabies mite-infested patients with clinical signs and symptoms of 1-2 weeks. In addition, the skin biopsies of three naïve individuals with no history of skin allergy were also included in the analysis as controls to avoid any confounding in inflammatory host immune responses and allow data comparison and interpretation with the porcine model. The patient and control samples data along with some demographic details is provided in Supplementary Table 1. RNA extracted from all eight skin biopsy samples showed a good RIN value ranging between 7.6 to 8.6 (Supplementary Figure 1).

\section{Identification of Dysregulated Gene Expression Profile in Infested Samples}

We carried out paired-end RNA-sequencing for freshly frozen skin biopsy samples. RNA-seq data exhibited good quality with almost 30 million reads per sample. Approximately 90-96\% raw reads successfully mapped to human reference transcriptome hg38 (Supplementary Table 2). An early exploratory PCA plot using all raw counts in the dataset showed an overall distinct transcriptomic pattern of raw counts from scabies and control sample profiles (Figure 2A). Differential expression analysis revealed that a large number of genes were significantly dysregulated, with 1,618 upregulated and 1,636 downregulated genes ( $\mathrm{p}$-value $<0.05$ and absolute $\log \mathrm{FC}>2$ ) in mite-infested samples compared to the control group (Figure 2B). The top thousand differentially expressed genes were visualized using unsupervised clustering. Clustering patterns showed that upregulated and downregulated genes grouped together in two distinct clusters. Notably, sample-wise clustering also revealed homogenous gene expression within each subgroup (three control and five mite-infested samples) with the greatest variability across the group. Within the mite-infested group, samples showed partial clustering with respect to the duration of exposure, hence indicating that transcriptomic changes mediated by mite infestation might be a time-dependent mechanism (Figure 2C). Top upregulated genes displayed a role in inflammatory responses and innate immunity (DEFB4A, IL-19, CXCL8, CSF3, SERPINB4, S100A7A, HRNR), keratinization (KRT9, KRT6C, EGR4, SPRR3, LCE3A, SPRR2A, LCE3A), and a gene involved in desquamation processes in skin (SPINK9); antigen recognition genes, binding of immunoglobulin genes (IGLV6-57, IGHV3-30, IGLV4-69, IGHEP1), and T-cell receptor gene (TRBV13) were the top downregulated in infested samples. Furthermore, genes involved in detoxification and homeostasis (FUT9 and UGT2B28) and hydrolase and peptidase activity (PM20D1) also showed more than five-fold downregulation in diseased samples. Interestingly, AADACL3 was remarkably downregulated. The chromosomal locus of the AADACL3 gene has been previously reported in recurrent Norwegian scabies samples (33). The top 20 up- and downregulated genes are listed in Table 1. 

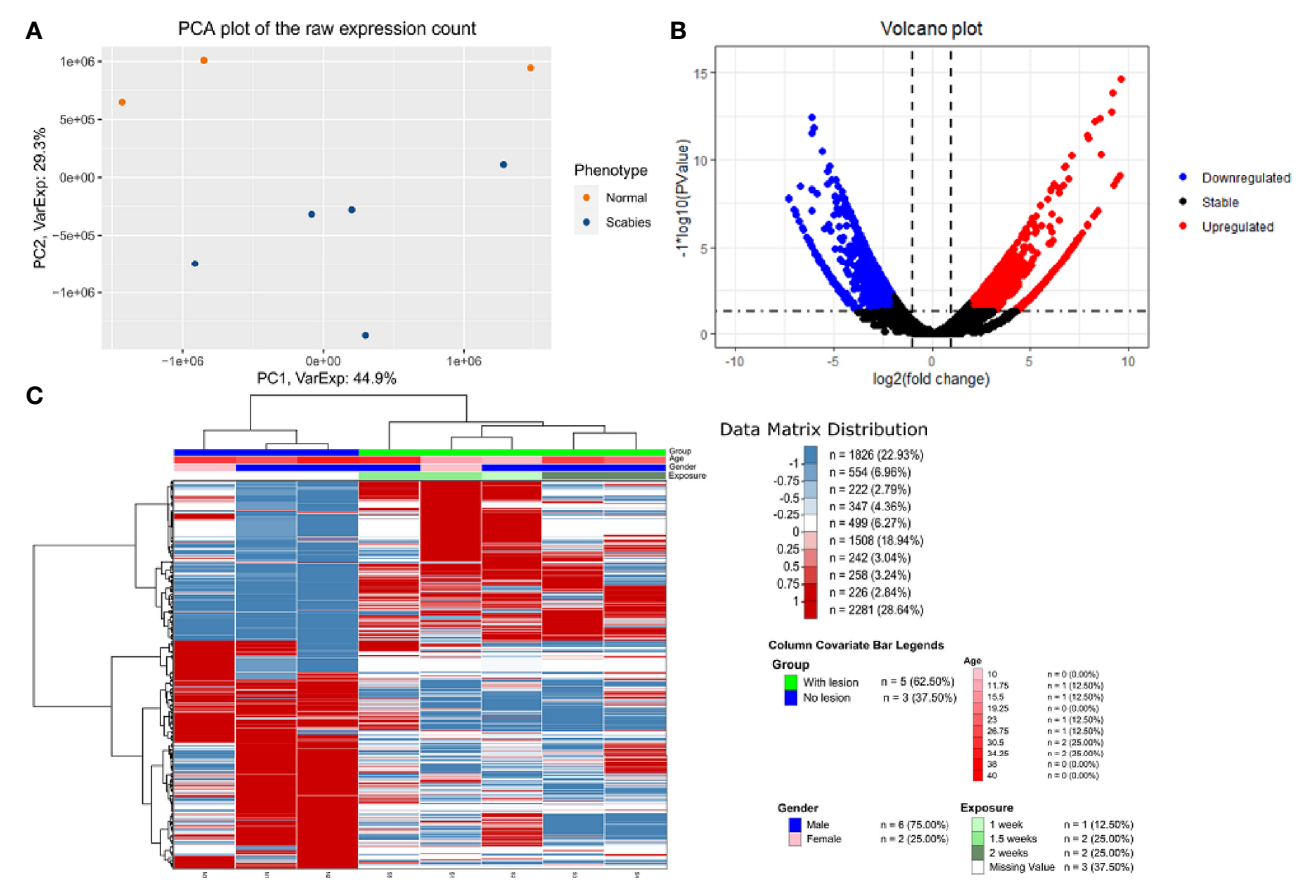

FIGURE 2 | Transcriptome profile of human skin biopsies infested with mite (S. scabiei var. hominis) (A) PCA plot using raw RNA-seq expression counts of eight samples (three control and five OS samples). (B) Volcano plot of differential expression profile of all genes with upregulated ( $p<0.05$ and logFC $>2$ ) and downregulated $(\mathrm{p}<0.05$ and logFC $<2$ ) genes shown in red and blue respectively. (C) NGCHM plot of top 1,000 differentially expressed genes using unsupervised hierarchical clustering in both directions (rows and columns). Covariates include age, gender, and duration of exposure and diseased group (With lesion represents OS samples, and No lesion represents control samples).

\section{Functional Impact of Dysregulated Gene in Infested vs. Control Samples}

Functional analysis was conducted at two levels, i.e., pathway enrichment analysis using differentially expressed genes $(\mathrm{p}<0.05$ and abs $\log \mathrm{FC}>2$ ) and Gene Set Enrichment Analysis (GSEA) using raw counts data. The enriched pathways in differentially expressed genes are shown in Figure 3. As expected, the results showed that pathways associated with skin development, including keratinization, epidermis development, and keratinocyte differentiation, were highly upregulated in the diseased samples. In addition, early immune-related responses including cytokine activity, chemokine signaling pathways, monocyte chemotaxis, and chemokine receptor binding are also upregulated in infested transcriptomic profiles. Notably, JAK-STAT pathway is upregulated in scabies-infested samples. Cell adhesion, negative regulation of Wnt signaling, calcium ion binding, scavenger receptor activity, retinol metabolism, and developmental processes were downregulated on the onset of infestation (Figure 3).

Likewise, gene set enrichment analysis using Gene OntologyBiological processes validated marked upregulation of a diverse range of early immune regulation pathways, leukocyte chemotaxis and migration, lymphocyte and $\mathrm{CD} 4^{+} \mathrm{T}$ cell differentiation, and skin development and differentiation (Figure 4). The biological process showed obvious downregulation in cellular catabolic process, tissue morphogenesis, cellular response to growth factors, cellular adhesion, and tissue developmental processes.
Densely connected network of GO terms not only indicated the robustness of the analysis but also validated the differential expression-based gene ontology results. GSEA analysis also highlighted multiple metabolic processes along with developmental processes in downregulated pathways (Figure 4).

\section{Pattern of Itch-Associated Genes of Mite-Infested Human Skin Biopsies (GSE178563)}

DEGs analysis identified itch-associated genes in mite-infested human skin biopsies (GSE178563) as represented in bar plot (Figure 5). DEGs in scabies mite-infested skin included those encoding certain chemokines (C-C motif) ligands CCL2, CCL17, and CCL 18, (C-X-C motif) ligand CXCL1, IL-17A, IL-17F, IL-23, IL-31 with FC greater than two for most of the genes. IL-4, CCL7, CCL20, IL-19, IL-20, IL-36A were also prominent DEGs with high FCs that were significantly correlated with the itch severity scores. Phospholipase A2 (PLA2) group IV PLA2G4D and S100A9 and A7 were also increased in itchy skin. In addition, the histamine receptor $3(\mathrm{HRH} 3)$ and serotonin receptor (HTR) 3C were also dominantly upregulated in scabies along with neuropeptide genes that are specifically present in human scabies DEGs list, i.e., Kappa-type opioid receptor OPRK1 and neuronal acetylcholine receptor subunit alpha 9 (CHRNA9) genes involved in neuropeptide signaling pathway and calcium channel activity, respectively. 
TABLE 1 | Top 20 upregulated and downregulated genes in mite-infested human skin biopsies $(n=5)$ with respect to control samples $(n=3)$.

\begin{tabular}{|c|c|c|c|c|c|c|}
\hline & Ensembl Gene ID & HGNC Symbol & $\log \mathrm{FC}$ & $\log C P M$ & PValue & FDR \\
\hline \multirow[t]{20}{*}{ Upregulated genes } & ENSG00000171711 & DEFB4A & 12.76 & 3.96 & $1.71 \mathrm{E}-15$ & $2.34 \mathrm{E}-11$ \\
\hline & ENSG00000142224 & IL19 & 10.76 & 6.10 & 4.04E-16 & 8.35E-12 \\
\hline & ENSG00000206073 & SERPINB4 & 10.58 & 6.85 & 1.93E-16 & $7.98 \mathrm{E}-12$ \\
\hline & ENSG00000171403 & KRT9 & 9.62 & 11.71 & $2.27 \mathrm{E}-15$ & $2.34 \mathrm{E}-11$ \\
\hline & ENSG00000135625 & EGR4 & 9.58 & 0.81 & 8.08E-10 & 1.59E-06 \\
\hline & ENSG00000166670 & MMP10 & 9.45 & 0.68 & 1.37E-09 & 2.37E-06 \\
\hline & ENSG00000108342 & CSF3 & 9.26 & 0.50 & 2.93E-09 & 4.02E-06 \\
\hline & ENSG00000170465 & KRT6C & 9.19 & 9.90 & $1.42 \mathrm{E}-14$ & 1.17E-10 \\
\hline & ENSG00000184330 & S100A7A & 9.16 & 4.89 & $1.75 \mathrm{E}-13$ & 1.20E-09 \\
\hline & ENSG00000204909 & SPINK9 & 8.63 & 1.51 & $4.55 E-11$ & 1.25E-07 \\
\hline & ENSG00000169429 & CXCL8 & 8.59 & 4.67 & 4.33E-13 & 2.23E-09 \\
\hline & ENSG00000171450 & CDK5R2 & 8.44 & -0.28 & 7.48E-08 & 5.33E-05 \\
\hline & ENSG00000163209 & SPRR3 & 8.40 & -0.31 & 8.86E-08 & 5.90E-05 \\
\hline & ENSG00000197915 & HRNR & 8.32 & 6.41 & $6.73 \mathrm{E}-13$ & 3.09E-09 \\
\hline & ENSG00000258397 & BCAR1P1 & 8.26 & -0.46 & $1.52 \mathrm{E}-07$ & 8.71E-05 \\
\hline & ENSG00000185962 & LCE3A & 7.97 & 5.19 & 5.77E-12 & $1.83 \mathrm{E}-08$ \\
\hline & ENSG00000215151 & ABCD1P2 & 7.96 & -0.74 & 4.88E-07 & 2.26E-04 \\
\hline & ENSG00000241794 & SPRR2A & 7.94 & 6.49 & $3.72 \mathrm{E}-12$ & $1.28 \mathrm{E}-08$ \\
\hline & ENSG00000259098 & & 7.92 & -0.77 & 5.69E-07 & 2.55E-04 \\
\hline & ENSG00000226807 & $\mathrm{MROH} 5$ & 7.65 & -1.01 & 1.57E-06 & 5.51E-04 \\
\hline \multirow[t]{20}{*}{ Downregulated genes } & ENSG00000211640 & IGLV6-57 & -7.29 & -1.86 & 1.57E-08 & 1.47E-05 \\
\hline & ENSG00000270550 & IGHV3-30 & -7.25 & -1.89 & 1.83E-08 & 1.64E-05 \\
\hline & ENSG00000211637 & IGLV4-69 & -7.02 & -2.07 & 6.86E-08 & 5.06E-05 \\
\hline & ENSG00000273018 & FAM106A & -6.98 & -2.10 & 8.20E-08 & 5.64E-05 \\
\hline & ENSG00000240708 & LINC02030 & -6.91 & -2.15 & 1.43E-07 & 8.55E-05 \\
\hline & ENSG00000251027 & LINC01950 & -6.76 & -2.27 & 3.16E-07 & 1.61E-04 \\
\hline & ENSG00000253692 & IGHEP1 & -6.69 & -1.14 & 3.02E-09 & 4.02E-06 \\
\hline & ENSG00000135226 & UGT2B28 & -6.61 & -2.36 & $7.48 \mathrm{E}-07$ & $3.12 \mathrm{E}-04$ \\
\hline & ENSG00000229453 & SPINK8 & -6.54 & -2.42 & 9.39E-07 & 3.66E-04 \\
\hline & ENSG00000235584 & & -6.39 & -2.52 & 2.47E-06 & 7.96E-04 \\
\hline & ENSG00000187481 & HSD3BP1 & -6.38 & -2.53 & 2.47E-06 & 7.96E-04 \\
\hline & ENSG00000205456 & TP53TG3D & -6.29 & -2.59 & 4.16E-06 & 1.18E-03 \\
\hline & ENSG00000223342 & & -6.24 & -2.64 & 4.16E-06 & 1.18E-03 \\
\hline & ENSG00000276405 & TRBV13 & -6.15 & -2.69 & 7.21E-06 & 1.86E-03 \\
\hline & ENSG00000172461 & FUT9 & -6.12 & -1.55 & 8.07E-08 & 5.64E-05 \\
\hline & ENSG00000124935 & SCGB1D2 & -6.10 & 6.65 & $3.68 \mathrm{E}-13$ & 2.17E-09 \\
\hline & ENSG00000277010 & & -6.10 & -1.01 & 5.14E-09 & 6.06E-06 \\
\hline & ENSG00000188984 & AADACL3 & -6.09 & 1.77 & $2.90 \mathrm{E}-12$ & 1.09E-08 \\
\hline & ENSG00000152591 & DSPP & -6.08 & -2.71 & 9.61E-06 & $2.28 \mathrm{E}-03$ \\
\hline & ENSG00000162877 & PM20D1 & -6.02 & 3.05 & 1.44E-12 & 5.92E-09 \\
\hline
\end{tabular}

\section{Comparative Transcriptomic Analysis}

We searched GEO and Array Express databases to identify previously performed gene expression studies on S. scabieiinfested samples. Although we did not find any existing transcriptome profiling using human skin biopsies, two ex-vivo models on artificially infested porcine samples and human skin equivalents E-MTAB-6433 (23) and GSE48459 (24) were previously compared with the pertinent comparison groups. Herein, we have performed comparative analysis of each of these studies with our model to identify a robust gene signature.

\section{Association Between Mite-Infested Human Skin Biopsies (GSE178563) and Ex-Vivo Porcine Infested Model (E-MTAB-6433)}

Recently, Bhat et al. employed a porcine model to study timemediated gene expression profiles from different scabies subtypes. The transcriptomic profile of porcine model was periodically observed over five different time points (Week 0 , $1,2,4,8)$ and three different comparison groups, i.e., crusted scabies (CS), ordinary scabies (OS), and control samples (23). The study compared all 15 combinations with the respective controls (i.e., five time points and three comparison groups) and presented the associated list of differentially expressed genes in their research article. Herein, we retrieved the human orthologs of differentially expressed gene lists and performed the association analysis of each comparison from porcine model with mite-infested human biopsies dataset (GSE178563). We identified human orthologs for more than $80 \%$ of the porcine differentially expressed genes, 9 to $53 \%$ of those retrieved human orthologs also showed significant differential expression in the mite-infested human skin biopsies (Table 2). Although earlier time points of porcine model showed no association with human infested samples, two groups of porcine models at week 8 showed a significant positive association with human biopsy dataset, and genes are conserved between human and porcine database (Figure 6A and Supplementary Table 3).

Crusted scabies vs. control (E-MTAB-6433) at week 8 exhibited a positive association with human infested biopsies 
A
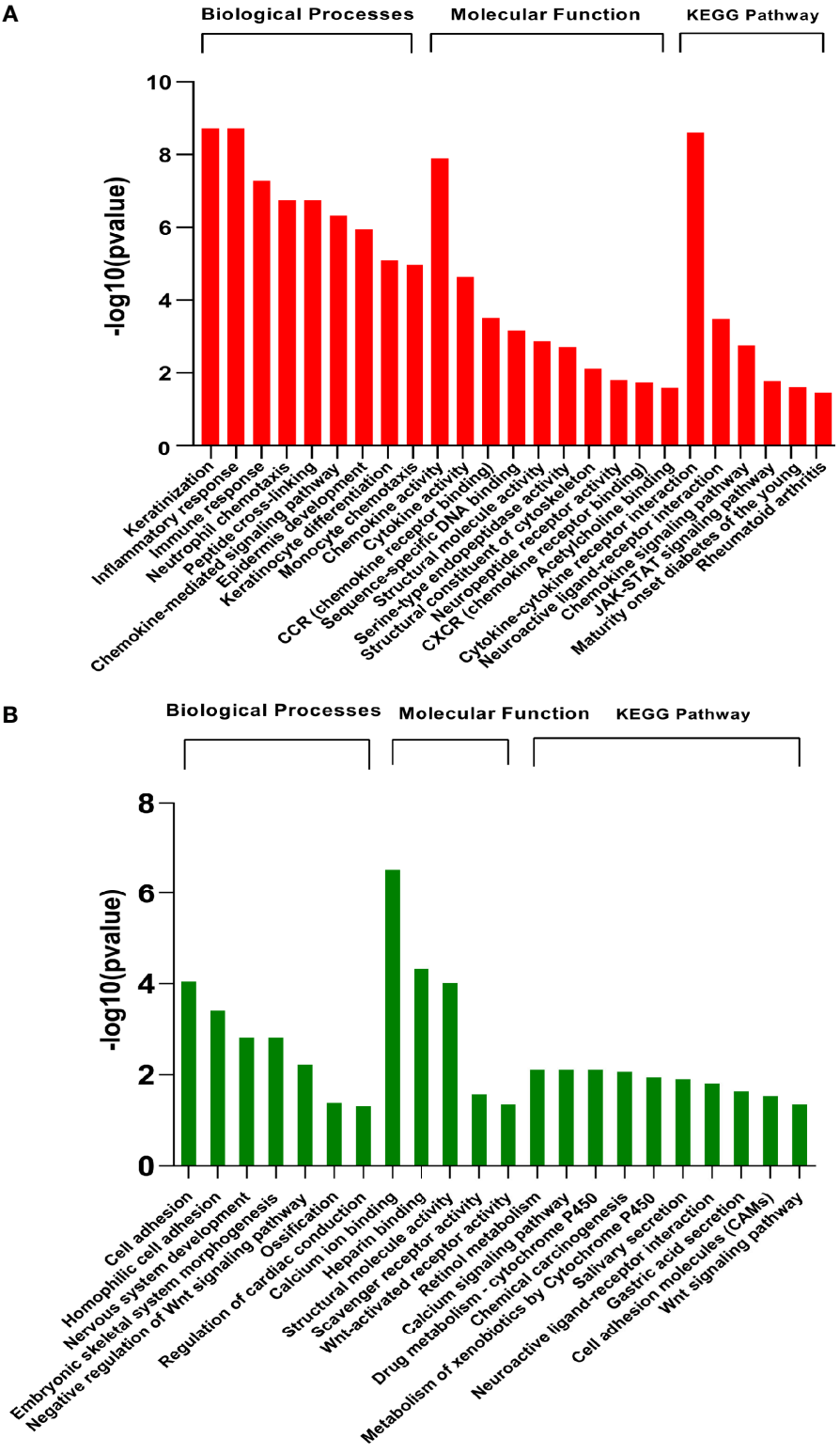

FIGURE 3 | Pathway enrichment analysis of differentially expressed genes (GSE178563). Significantly (A) upregulated and (B) downregulated pathways (FDR<0.05) enriched in differentially expressed genes using Gene Ontology biological processes, molecular function, and KEGG database by DAVID web tool.

$(\mathrm{OR}=5.36 ; \mathrm{p}=8.86 \mathrm{e}-04$; Figure $6 \mathrm{~B})$ such that the number of genes dysregulated in the same direction (38 genes upregulated and 25 genes downregulated in both profiles) was significantly more than the genes regulated in the opposite direction ( 29 genes upregulated in porcine model and downregulated in human skin biopsies; 6 genes downregulated in porcine model and upregulated in human skin biopsies) (Figure 6B). Fold change of CS vs. OS porcine model also showed a significant positive correlation with mite-infested human dataset $(R=0.36$; $p=7.6 e-06$; Figure 6C). Similar to comparative analysis of CS $v s$. C with mite-infested human biopsies, shared upregulated profile in CS vs. OS and human infested biopsies also exhibited marked enrichment of immune response pathways (Cytokine and chemokine signaling, JAK-STAT signaling, IL-4 and IL-13 pathway, and Toll receptor cascade). Likewise, we observed a direct association between CS vs. OS (week 8) and mite-infested human skin biopsy samples $(\mathrm{OR}=5.04$; $\mathrm{p}=2.07 \mathrm{e}-05$; Figure 6D). High odd ratio and significant fishers exact test results revealed that the concordant transcriptomic changes (29 shared upregulated and 73 downregulated genes) outnumbered the discordant gene profile (13 genes upregulated in porcine CS $v$. OS and downregulated in human skin biopsies; 33 genes downregulated in porcine CS $v s$. OS and upregulated in human skin biopsies) (Figure 6D). The fold changes also exhibited a 


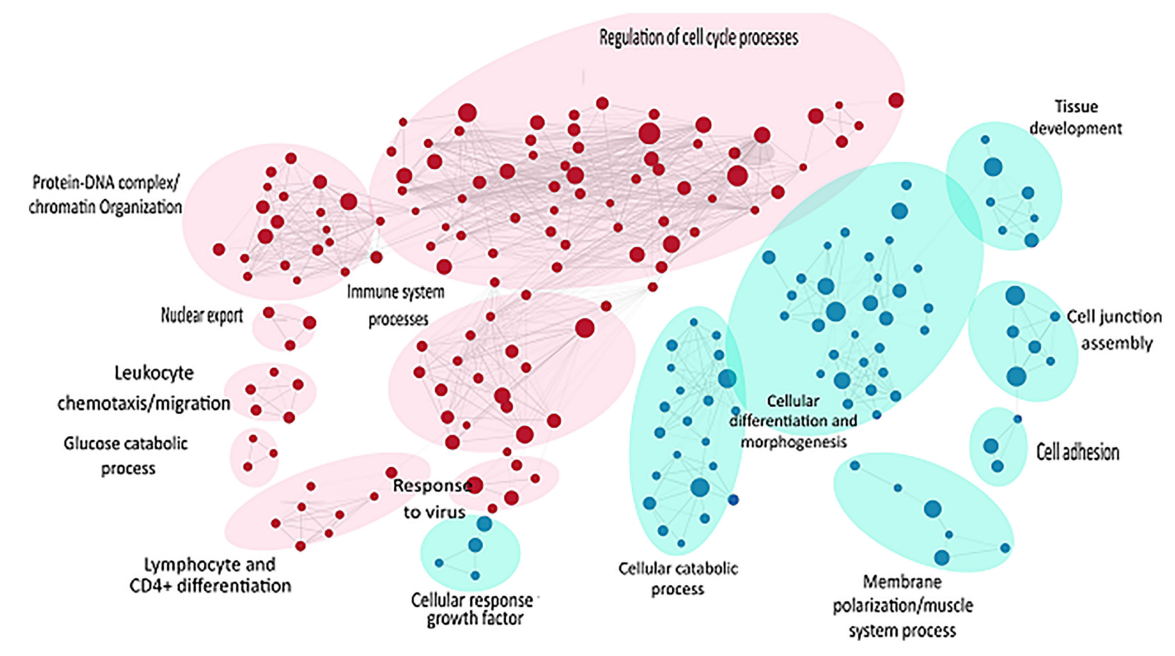

FIGURE 4 | GSEA of raw counts data using Gene Ontology-Biological processes. Pathways upregulated in OS diseased samples are shown in red, while pathways enriched in control samples are shown in blue. Node size indicates size of that gene set, and edge width indicates the similarity coefficient between two gene sets.

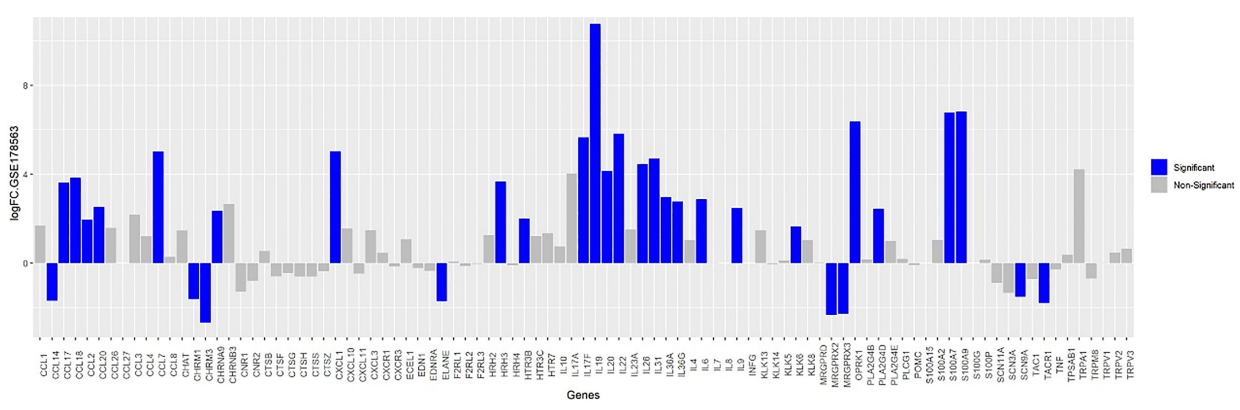

FIGURE 5 | Bar plot of itch-associated genes of GSE178563 (mite-infested human skin biopsies).

linear positive correlation between the two profiles $(\mathrm{R}=0.46$, $\mathrm{p}=1.7 \mathrm{e}-06$; Figure $6 \mathrm{E}$ ).

Furthermore, we performed the functional analysis using shared gene profiles and found that set of genes upregulated in both profiles [Porcine model CS vs. C (Week 8) and human infested skin biopsies] were largely enriched with immune component including "Chemokine signaling pathway, Interleukin-4 and Interleukin-13 signaling, Innate Immune System, Cytokine Signaling in Immune system, and JAK-STAT signaling pathway." Shared downregulated genes $(\mathrm{n}=25)$ showed an enrichment of PPAR and nuclear signaling pathways. We also observed that genes related to cellular transport, metabolism, and homeostasis were upregulated in porcine CS vs. C but downregulated in mite-infested human biopsies (Table 3). Contrarily, the downregulated profile did not show enrichment of any signaling pathway, but metabolism of amine-derived hormone was enriched in the discordant gene set (upregulated in porcine and downregulated in humans). Complete data for both porcine model (CS vs. C and CS vs.
OS) merged with the human dataset is available in Supplementary Tables 4 and 5, respectively. Unlike the comparison of CS vs. OS and CS vs. C with human data, the third porcine comparison group (OS vs. C) did not show association with human infested biopsies at any given time point, thus indicating a distinct transcriptome profile. Given the shared upregulation of immune component in the three groups, we combined a signature of two significant groups from porcine infested group, i.e., both porcine groups (CS $v s$. OS and CS vs. C; Week 8) with human infested samples separately for up- and downregulated genes (Figures 6F, G). Herein, we identified that 18 genes were commonly upregulated in all three groups (CS vs. C, CS vs. OS and human infested skin biopsies; Figures 6F, G). As expected, shared upregulated genes primarily included chemokine ligands and receptors (CCL17, CCL18, CCL3L1, CCL3L3, CCR7) and cytokines (IL13 and IL-20), calcium-binding proteins (S100A2 and S100A8), genes involved in B Cell Receptor Signaling Pathway (sino) and B cell receptor signaling pathway (KEGG) (BCL2A1), fatty acid 
TABLE 2 | Number of differentially expressed genes in mite-infested porcine and human samples.

\begin{tabular}{|c|c|c|c|c|c|c|}
\hline $\begin{array}{l}\text { Porcine } \\
\text { comparison } \\
\text { groups }\end{array}$ & $\begin{array}{c}\text { Time } \\
\text { series }\end{array}$ & $\begin{array}{l}\text { Number of DE genes in } \\
\text { mite-infested porcine } \\
\text { groups (E-MTAB-6433) }\end{array}$ & $\begin{array}{c}\text { Number of human } \\
\text { orthologs } \\
\text { (Ensembl } \\
\text { Biomart) }\end{array}$ & $\begin{array}{l}\% \text { of retrieved human } \\
\text { ortholog w.r.t. number of } \\
\text { DEGs in porcine group }\end{array}$ & $\begin{array}{l}\text { DEGs in mite-infested } \\
\text { human skin biopsies } \\
\text { (GSE178563; p<0.05) }\end{array}$ & $\begin{array}{l}\% \text { of DEGS in human } \\
\text { samples w.r.t. total number } \\
\text { of retrieved orthologs }\end{array}$ \\
\hline \multirow[t]{5}{*}{ CS-C } & Week 0 & 1,552 & 1,290 & $83.12 \%$ & 153 & $11.86 \%$ \\
\hline & Week 1 & 1,202 & 1,015 & $84.44 \%$ & 114 & $11.23 \%$ \\
\hline & Week 2 & 1,272 & 1,067 & $83.88 \%$ & 105 & $9.84 \%$ \\
\hline & Week 4 & 367 & 306 & 83.38\% & 45 & $14.71 \%$ \\
\hline & Week 8 & 1,006 & 842 & $83.70 \%$ & 98 & $11.64 \%$ \\
\hline \multirow[t]{5}{*}{ OS-C } & Week 0 & 344 & 287 & $83.43 \%$ & 34 & $11.85 \%$ \\
\hline & Week 1 & 952 & 797 & $83.72 \%$ & 75 & $9.41 \%$ \\
\hline & Week 2 & 1,955 & 1,640 & 83.89\% & 181 & $11.04 \%$ \\
\hline & Week 4 & 758 & 622 & $82.06 \%$ & 84 & $13.50 \%$ \\
\hline & Week 8 & 1,573 & 1,322 & $84.04 \%$ & 154 & $11.65 \%$ \\
\hline \multirow[t]{5}{*}{ CS-OS } & Week 0 & 1,297 & 1,072 & $82.65 \%$ & 572 & $53.36 \%$ \\
\hline & Week 1 & 1,305 & 1,074 & $82.30 \%$ & 108 & $10.06 \%$ \\
\hline & Week 2 & 1,651 & 1,366 & $82.74 \%$ & 148 & $10.83 \%$ \\
\hline & Week 4 & 261 & 217 & $83.14 \%$ & 22 & $10.14 \%$ \\
\hline & Week 8 & 1,292 & 1,081 & $83.67 \%$ & 149 & $13.78 \%$ \\
\hline
\end{tabular}

binding protein in epidermal call and as glycerol transport in skin (FABP5, AQP3, HAS3) and genes that express the cytokines and skin barrier protein in human keratinocytes (S100A12, S100A8) (Figure 6F). We observed that eight genes including androgen receptor and negative regulator of Wnt (SHISA2) were commonly downregulated in all three signatures (Figure 6G).

\section{Association of Mite-Infested Human Skin Biopsies (GSE178563) With Human Skin Equivalents (GSE48459)}

The human skin equivalents were employed to identify the gene signature that responds to burrowing of scabies mite (GSE48459)
(24). Herein, we compared infested human skin equivalents with infested skin biopsy transcriptomics profile (GSE178563). Although the original study compared three different groupscontrols, live mites, and mite extract-we employed the live mites vs. control group for comparison with our mite-infested human skin biopsy transcriptome (GSE178563). We found a significant positive correlation between $\operatorname{logFC}$ of both datasets $(\mathrm{R}=0.21, \mathrm{p}=3 \mathrm{e}-07$; Figure 7A). Association analysis between both datasets (skin biopsy and in-vitro skin equivalent) aligned with the porcine comparative analysis presented in the previous section. We observed that both human-based transcriptomic profiles exhibited a direct association with an odds ratio of
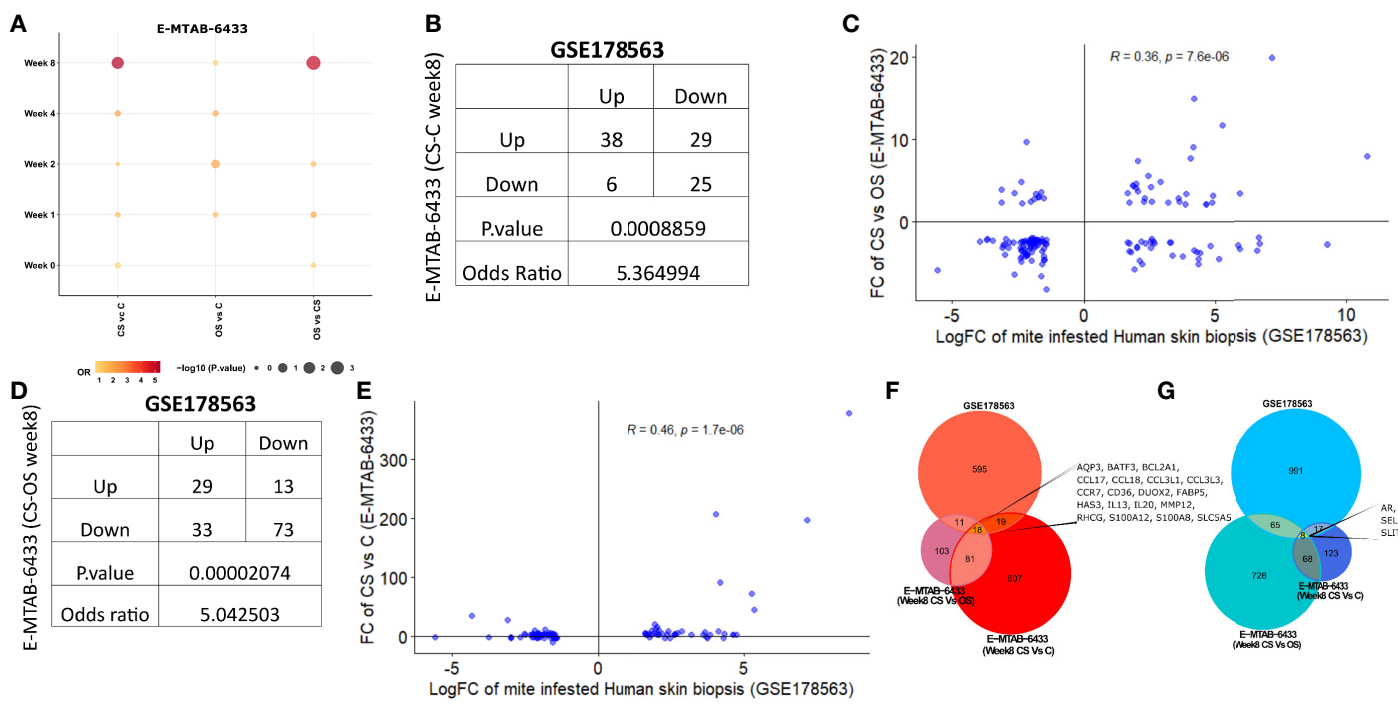

G

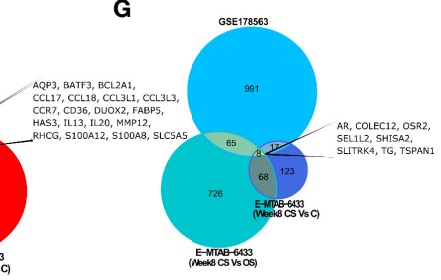

FIGURE 6 | Comparative analysis of GSE178563 (mite-infested human skin biopsies) with E-MTAB-6433 (mite-infested pig biopsies). (A) Association between significantly modulated differential expression profiles of human infested skin biopsies with each time point (Week $0,1,2,4,8$ ) of porcine infested groups. Association statistics (contingency table along with odds ratio and fisher's exact p-value) and correlation plots of significant porcine groups, i.e (1)., CS vs. C (B, C) and (2) CS vs. OS (D, E). Combined Venn diagram of all significantly associated groups identified in (F, G) (Week 8 CS vs. C and Week 8 CS vs. OS mite-infested human samples vs. control). 
TABLE 3 | KEGG pathway enrichment of common genes in mite-infested human (Scabies vs. control) and porcine groups (Week 8; CS vs. OS and CS vs. C)

\begin{tabular}{|c|c|c|c|c|c|c|c|}
\hline $\begin{array}{l}\text { Comparison } \\
\text { Group }\end{array}$ & $\begin{array}{l}\text { Disease } \\
\text { condition in } \\
\text { Human and } \\
\text { Pigs }\end{array}$ & Gene Set Name & $\begin{array}{l}\text { \# Genes } \\
\text { in Gene } \\
\text { Set (K) }\end{array}$ & Description & $\begin{array}{l}\# \text { Genes } \\
\text { in } \\
\text { Overlap } \\
\text { (k) }\end{array}$ & $k / K$ & $\begin{array}{l}\text { FDR } \\
\text { q-value }\end{array}$ \\
\hline \multirow{20}{*}{$\begin{array}{l}\text { CS Vs. C } \\
\text { (Week 8) } \\
\text { porcine } \\
\text { model and } \\
\text { mite } \\
\text { infested } \\
\text { human skin } \\
\text { biopsies }\end{array}$} & \multirow[t]{12}{*}{$\begin{array}{l}\text { Commonly } \\
\text { Upregulated }\end{array}$} & GOBP_RESPONSE_TO_ENDOGENOUS_STIMULUS & 1624 & $\begin{array}{l}\text { Any process that results in a change in state or activity } \\
\text { of a cell or an organism (in terms of movement, } \\
\text { secretion, enzyme production, gene expression, etc.) } \\
\text { as a result of a stimulus arising within the organism. } \\
\text { [GOC:sm] }\end{array}$ & 9 & $\begin{array}{c}5.50 \mathrm{E}- \\
03\end{array}$ & $\begin{array}{c}1.25 \mathrm{E}- \\
03\end{array}$ \\
\hline & & GOBP_CHEMICAL_HOMEOSTASIS & 1187 & $\begin{array}{l}\text { Any biological process involved in the maintenance of } \\
\text { an internal steady state of a chemical. [GOC: } \\
\text { isa_complete] }\end{array}$ & 8 & $\begin{array}{l}6.70 \mathrm{E}- \\
03\end{array}$ & $\begin{array}{l}1.25 \mathrm{E}- \\
03\end{array}$ \\
\hline & & KEGG_CYTOKINE_CYTOKINE_RECEPTOR_INTERACTION & 265 & Cytokine-cytokine receptor interaction & 9 & $\begin{array}{c}3.40 \mathrm{E}- \\
02\end{array}$ & $\begin{array}{c}3.79 \mathrm{E}- \\
09\end{array}$ \\
\hline & & REACTOME_SIGNALING_BY_INTERLEUKINS & 463 & Signaling by Interleukins & 9 & $\begin{array}{c}1.94 \mathrm{E}- \\
02\end{array}$ & $\begin{array}{l}2.70 \mathrm{E}- \\
07\end{array}$ \\
\hline & & REACTOME_CYTOKINE_SIGNALING_IN_IMMUNE_SYSTEM & 719 & Cytokine Signaling in Immune system & 10 & $\begin{array}{c}1.39 \mathrm{E}- \\
02\end{array}$ & $\begin{array}{c}4.12 \mathrm{E}- \\
07\end{array}$ \\
\hline & & REACTOME_CHEMOKINE_RECEPTORS_BIND_CHEMOKINES & 58 & Chemokine receptors bind chemokines & 5 & $\begin{array}{c}8.62 \mathrm{E}- \\
02\end{array}$ & $\begin{array}{l}9.73 \mathrm{E}- \\
07\end{array}$ \\
\hline & & KEGG_CHEMOKINE_SIGNALING_PATHWAY & 189 & Chemokine signaling pathway & 6 & $\begin{array}{l}3.17 \mathrm{E}- \\
02\end{array}$ & $\begin{array}{l}7.23 \mathrm{E}- \\
06\end{array}$ \\
\hline & & REACTOME_INTERLEUKIN_4_AND_INTERLEUKIN_13_SIGNALING & 111 & Interleukin-4 and Interleukin-13 signaling & 5 & $\begin{array}{c}4.50 \mathrm{E}- \\
02\end{array}$ & $\begin{array}{c}1.75 \mathrm{E}- \\
05\end{array}$ \\
\hline & & REACTOME_INNATE_IMMUNE_SYSTEM & 1117 & Innate Immune System & 9 & $\begin{array}{c}8.10 \mathrm{E}- \\
03\end{array}$ & $\begin{array}{l}1.48 \mathrm{E}- \\
04\end{array}$ \\
\hline & & REACTOME_PEPTIDE_LIGAND_BINDING_RECEPTORS & 198 & Peptide ligand-binding receptors & 5 & $\begin{array}{c}2.53 \mathrm{E}- \\
02\end{array}$ & $\begin{array}{c}2.33 \mathrm{E}- \\
04\end{array}$ \\
\hline & & REACTOME_NEUTROPHIL_DEGRANULATION & 479 & Neutrophil degranulation & 6 & $\begin{array}{l}1.25 \mathrm{E}- \\
02\end{array}$ & $\begin{array}{l}9.23 \mathrm{E}- \\
04\end{array}$ \\
\hline & & REACTOME_INTERLEUKIN_10_SIGNALING & 46 & Interleukin-10 signaling & 3 & $\begin{array}{c}6.52 \mathrm{E}- \\
02\end{array}$ & $\begin{array}{c}1.88 \mathrm{E}- \\
03\end{array}$ \\
\hline & \multirow[t]{3}{*}{$\begin{array}{l}\text { Commonly } \\
\text { Downregulated }\end{array}$} & KEGG_PPAR_SIGNALING_PATHWAY & 69 & PPAR signaling pathway & 4 & $\begin{array}{c}5.80 \mathrm{E}- \\
02\end{array}$ & $\begin{array}{c}1.73 \mathrm{E}- \\
04\end{array}$ \\
\hline & & $\begin{array}{l}\text { REACTOME_TRANSCRIPTIONAL_REGULATION_OF } \\
\text { _WHITE_ADIPOCYTE_DIFFERENTIATION }\end{array}$ & 84 & $\begin{array}{l}\text { Transcriptional regulation of white adipocyte } \\
\text { differentiation }\end{array}$ & 3 & $\begin{array}{l}3.57 \mathrm{E}- \\
02\end{array}$ & $\begin{array}{l}1.74 \mathrm{E}- \\
02\end{array}$ \\
\hline & & REACTOME_SIGNALING_BY_NUCLEAR_RECEPTORS & 297 & Signaling by Nuclear Receptors & 4 & $\begin{array}{c}1.35 \mathrm{E}- \\
02\end{array}$ & $\begin{array}{c}1.93 \mathrm{E}- \\
02\end{array}$ \\
\hline & $\begin{array}{l}\text { Downregulated } \\
\text { in Porcine and } \\
\text { Upregulated in } \\
\text { Humans }\end{array}$ & No enrichment & & & & & \\
\hline & \multirow{4}{*}{$\begin{array}{l}\text { Upregulated in } \\
\text { Porcine and } \\
\text { downregulated } \\
\text { in Humans }\end{array}$} & REACTOME_TRANSPORT_TO_THE_GOLGI_AND_SUBSEQUENT_MODIFICATION & 186 & Transport to the Golgi and subsequent modification & 4 & $\begin{array}{l}2.15 \mathrm{E}- \\
02\end{array}$ & $\begin{array}{l}1.70 \mathrm{E}- \\
02\end{array}$ \\
\hline & & REACTOME_THYROXINE_BIOSYNTHESIS & 10 & Thyroxine biosynthesis & 2 & $\begin{array}{c}2.00 \mathrm{E}- \\
01\end{array}$ & $\begin{array}{c}2.01 \mathrm{E}- \\
02\end{array}$ \\
\hline & & $\begin{array}{l}\text { REACTOME_TFAP2_AP_2_FAMILY_REGULATES_TRANSCRIPTION_ } \\
\text { OF_GROWTH_FACTORS_AND_THEIR_RECEPTORS }\end{array}$ & 15 & $\begin{array}{l}\text { TFAP2 (AP-2) family regulates transcription of growth } \\
\text { factors and their receptors }\end{array}$ & 2 & $\begin{array}{c}1.33 \mathrm{E}- \\
01\end{array}$ & $\begin{array}{l}2.69 \mathrm{E}- \\
02\end{array}$ \\
\hline & & REACTOME_ASPARAGINE_N_LINKED_GLYCOSYLATION & 305 & Asparagine $\mathrm{N}$-linked glycosylation & 4 & & \\
\hline
\end{tabular}


REACTOME_METABOLISM_OF_AMINE_DERIVED_HORMONES

REACTOME_CLASS_A_1_RHODOPSIN_LIKE_RECEPTORS

GOBP_ENZYME_LINKED_RECEPTOR_PROTEIN_SIGNALING_PATHWAY

GOBP TRANSMEMBRANE RECEPTOR_PROTEIN TYROSINE KINASE_SIGNALING_PATHWAY

GOBP_REGULATION_OF_CELLULAR_RESPONSE_TO_ GROWTH_FACTOR_STIMULUS

GOBP_CELL_MIGRATION

GOBP_TRANSMEMBRANE_TRANSPORT

GOMF_MOLECULAR_TRANSDUCER_ACTIVITY

GOBP_LOCOMOTION

GOBP_ION_HOMEOSTASIS

$\begin{array}{ll}\text { CS Vs. OS } & \text { Commonly } \\ \text { (Week 8) } & \text { Upregulated }\end{array}$

(Week 8)

model and

mite

KEGG_CYTOKINE_CYTOKINE_RECEPTOR_INTERACTION

REACTOME_SIGNALING_BY_INTERLEUKINS

REACTOME_CYTOKINE_SIGNALING_IN_IMMUNE_SYSTEM
18 Metabolism of amine-derived hormones

331 Class A/1 (Rhodopsin-like receptors)

1072 Any series of molecular signals initiated by the binding of an extracellular ligand to a receptor on the surface of the target cell, where the receptor possesses catalytic activity or is closely associated with an enzyme such as a protein kinase, and ending with regulation of a downstream cellular process, e.g. transcription. [GOC: mah, GOC:signaling, ISBN:0815316194]

737 A series of molecular signals initiated by the binding of an extracellular ligand to a receptor on the surface of the target cell where the receptor possesses tyrosine kinase activity, and ending with regulation of a downstream cellular process, e.g. transcription. [GOC: ceb, GOC:signaling]

296 Any process that modulates the rate, frequency, or extent of a change in state or activity of a cell (in terms of movement, secretion, enzyme production, gene expression, etc.) as a result of a growth factor stimulus. [GOC:tb]

1602 The controlled self-propelled movement of a cell from one site to a destination guided by molecular cues. Cell migration is a central process in the development and maintenance of multicellular organisms. [GOC:cjm,

GOC:dph, GOC:ems, GOC:pf, Wikipedia:

Cell_migration]

1605 The process in which a solute is transported across a lipid bilayer, from one side of a membrane to the other. [GOC:dph, GOC:jid]

1489 A compound molecular function in which an effector function is controlled by one or more regulatory

components. [GOC:dos, GOC:pdt]

1975 Self-propelled movement of a cell or organism from one location to another. [GOC:dgh]

787 Any process involved in the maintenance of an internal steady state of ions within an organism or cell. [GOC:ai]

Cytokine-cytokine receptor interaction

463 Signaling by Interleukins

719 Cytokine Signaling in Immune system

.31E- $2.69 \mathrm{E}-$

$02 \quad 02$

$2 \quad 1.11 \mathrm{E}-2.69 \mathrm{E}-$

$\begin{array}{ccc} & 01 & 02 \\ 4 & 1.21 E- & 2.69 E-\end{array}$

$02 \quad 02$

$10 \quad 9.30 \mathrm{E}-\quad 1.97 \mathrm{E}-$

$03 \quad 05$

8 1.09E- 1.69E-

6 2.03E- $1.79 \mathrm{E}-$

$02 \quad 04$

$10 \quad 6.20 \mathrm{E}-\quad 1.79 \mathrm{E}-$

$03 \quad 04$ 
Comparison Disease

Group

condition in

Pigs
Gene Set Name

$$
\begin{gathered}
\text { \# Genes } \\
\text { in Gene } \\
\text { Set (K) }
\end{gathered}
$$

Description

\# Genes k/K FDR

in

Overip

(k)

\section{infested}

human skin

biopsies

Commonly

Downregulated

Downregulated

in Porcine and

Upregulated in

humans

Upregulated in REACTOME_METABOLISM_OF_AMINE_DERIVED_HORMONES

Porcine and

downregulated

in Humans
KEGG_JAK_STAT_SIGNALING_PATHWAY

REACTOME_CHEMOKINE_RECEPTORS_BIND_CHEMOKINES

KEGG_CHEMOKINE_SIGNALING_PATHWAY

REACTOME_THYROXINE_BIOSYNTHESIS

REACTOME_TOLL_LIKE_RECEPTOR_TLR1_TLR2_CASCADE

REACTOME_INTERLEUKIN 4 _AND_INTERLEUKIN_13 SIGNALING

REACTOME_IRAK4_DEFICIENCY_TLR2_4

$\begin{array}{ll}155 & \text { Jak-STAT signaling pathway } \\ 58 & \text { Chemokine receptors bind chemokines } \\ 189 & \text { Chemokine signaling pathway } \\ 10 & \text { Thyroxine biosynthesis } \\ 103 & \text { Toll Like Receptor TLR1:TLR2 Cascade } \\ 111 & \text { Interleukin-4 and Interleukin-13 signaling } \\ 18 & \text { IRAK4 deficiency (TLR2/4) }\end{array}$

No enrichment

\begin{tabular}{|c|c|c|}
\hline & & \\
\hline & 03 & 04 \\
\hline 4 & $\begin{array}{c}2.58 \mathrm{E}- \\
02\end{array}$ & $\begin{array}{c}2.07 \mathrm{E}- \\
03\end{array}$ \\
\hline 3 & $5.17 \mathrm{E}-$ & 3.03E- \\
\hline & 02 & 03 \\
\hline 4 & 2.12E- & $3.03 \mathrm{E}-$ \\
\hline & 02 & 03 \\
\hline 2 & $2.00 \mathrm{E}-$ & 5.73E- \\
\hline & 01 & 03 \\
\hline 3 & $2.91 \mathrm{E}-$ & $1.24 \mathrm{E}-$ \\
\hline & 02 & 02 \\
\hline 3 & $2.70 \mathrm{E}-$ & $1.24 \mathrm{E}-$ \\
\hline & 02 & 02 \\
\hline 2 & $1.11 \mathrm{E}-$ & $1.24 \mathrm{E}-$ \\
\hline & 01 & 02 \\
\hline
\end{tabular}

No enrichment

18 Metabolism of amine-derived hormones
$2 \quad 1.11 \mathrm{E}-2.62 \mathrm{E}-$ 
$2.17(\mathrm{p}=1.62 \mathrm{e}-05$; Figure $7 \mathbf{B})$, thus indicating that genes dysregulated in the same direction (i.e., concordantly up- or downregulated) were more pronounced than the ones in the opposite direction (Figure 7B). As expected, compared to the pig's dataset, GSE48459 had more genes in common with human skin biopsy dataset (Figures 7B-D). One hundred eighty shared upregulated genes were significantly enriched in chemotaxis, chemokine-mediated signaling pathway, inflammatory response, and keratinization (Figure $7 \mathbf{C}$ ). The set of downregulated genes did not show any significantly enriched pathway (Figure 7D). The complete merged data of both human (GSE178563) and human skin equivalent (GSE48495) is available in Supplementary Table 6.

\section{DISCUSSION}

S. scabiei var. hominis causes skin infestation in humans by forming burrows in the stratum corneum of the skin and feeding on host epidermis and sera. The release of active metabolites from the mite contribute to the intense itching and inflammation manifesting as a skin allergy and inflammatory responses (2). Potential sources of allergens include fecal material, mite bodies, mite saliva secreted at feeding, soluble proteins released after death in body fluids, and enzymes involved in molting and digestive processes (34). The interactions between host and parasite are of great concern. Our aim was to provide details about disease regulation and development in human scabies by giving an insight into any underlying predisposition for the diseased condition and determine the specific host immune responses and differentially expressed genes after mite infestation. Our study is the first extensive in vivo analysis in humans regarding the gene expression profiles in OS. We also compare our data with two scabies-related gene expression datasets, i.e., porcine model (E-MTAB6433) (23) and human skin equivalents (GSE48459) (24).

\section{Upregulated Immunity Genes}

The immunomodulatory effects of S. scabiei on the host assists in immune evasion and infestation and can be the possible reason for delayed clinical manifestation during primary infestation (35). The top upregulated gene associated to have a role in inflammatory responses in OS is DEFB4A, which is known to be induced by IL-17A in epidermal keratinocytes and reconstituted human epidermis $(36,37)$. Increased expression of DEFB4A (IL-17 signature gene) is linked with an increased number of CD3+, CD8+ T cells in psoriasis $(38,39)$ and reported to play an important role in the onset of asthma and atopy (40).

IL-19 is reported to have role in inflammation, vascularization, and tissue remodeling (41), and associated with induced Th2 cytokines in allergic patients. IL-19 binds the dimer receptor IL-20R leading to activation of the JAK/STAT signaling pathway (42). Additionally, it has been suggested IL-19 might act as an assessment tool for psoriasis and atopic dermatitis patients (43), and along with IL-23/IL-17, has strengthened its role as a biomarker for chronic inflammatory disorders (44).

CXCL8-encoded IL-8 was also upregulated in OS and has roles in inflammatory cell activation, initiation of inflammatory responses, and migration of neutrophils to sites of inflammation $(45,46)$. CXCL8 receptor expression has been mainly found in psoriasis keratotic lesions and contributes to severity of psoriasis by the release of inflammatory mediators and migration of neutrophils to lesion site $(47,48)$. Neutrophils initiate inflammation and mediate tissue destructive events in several inflammatory diseases $(49,50)$. Neutrophils were reported as prominent inflammatory cell infiltrate in cases of human scabies as well as scabies-infested wombats, sheep, and red foxes $(51,52)$.

CSF3 belongs to the IL-6 superfamily and is among the upregulated genes of OS. CSF3 has been shown to have a role in the inflammatory response, cytokine-mediated signaling pathways, and signal transduction, and known to be a factor involved in immune cell activation and recruitment in Psoroptes ovis (P. ovis) (21). CSF3 was one of the upregulated genes differentially expressed by human skin equivalents exposed to live scabies mites (24).

The SERPINB4 gene is upregulated in OS, which suggests it is more likely to be the part of acute response rather than a chronic effect (53-55). SERPINB4, first identified for its protease inhibition activity, has also been reported to have roles in controlling important innate immune pathways involving clotting, inflammation, and complement cascade (56). Interestingly, SERPINB4 is also found secreted in Sarcoptes mite gut and excreted out with mite feces into formed burrows. It has been shown to promote the growth of group A streptococcus (GAS) and S. aureus. This colonization of miteinfected skin with GAS, S. aureus, and other pathogens could be the reason of systemic infection and may lead to deleterious outcomes in patients with severe scabies (57). Additionally, other studies also reported the increased expression of SERPINB4 gene in skin and serum of psoriasis patients $(58,59)$.

Also included among the top upregulated DEGs is S100A7A. This has previously been identified among psoriasis-associated genes involved in activation and proliferation of keratinocytes, modulation of host immune response, and antimicrobial defense (59), and as a biomarker in atopic dermatitis (60), and also upregulated in scabies inflammatory processes (Bhat et al., 2020). S100A7A (psoriasin) is an antimicrobial peptide that also has roles in migration of keratinocytes, dendritic cells, and $\mathrm{T}$ lymphocytes and the activation of the innate and acquired immune response $(61,62)$.

HRNR, another upregulated gene of OS, has been recently reported to be considered a biomarker for differential diagnosis of atopic dermatitis (63) and expressed in human epidermal keratinocytes (64). GWAS (genome-wide association study) also revealed that upregulation of HRNR gene is one of the stronger risk factors for eczema, more than for hay fever or asthma (65). HRNR contributes to antimicrobial and protective functions in healthy skin, and its reduced expression is reported to be associated with epidermal barrier defects in atopic dermatitis infection (66). 


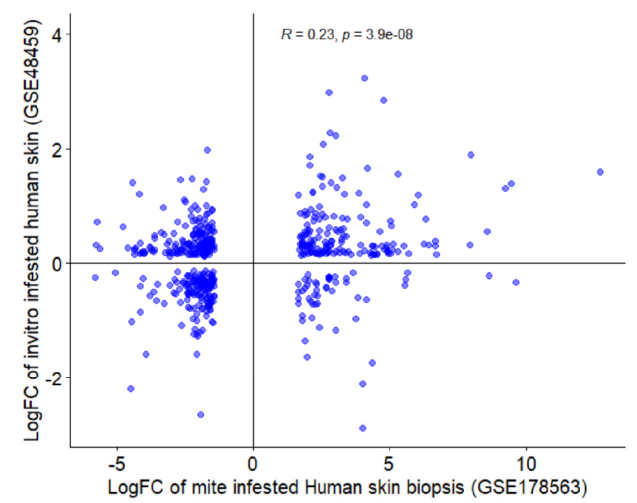

C

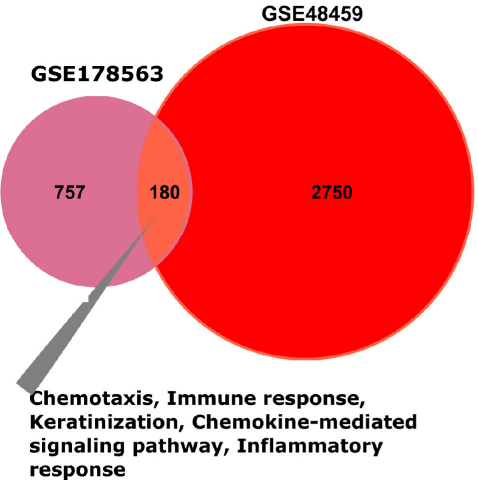

B

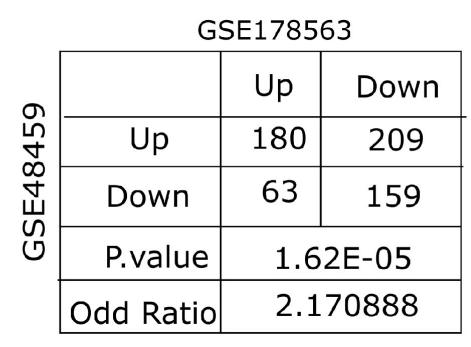

D

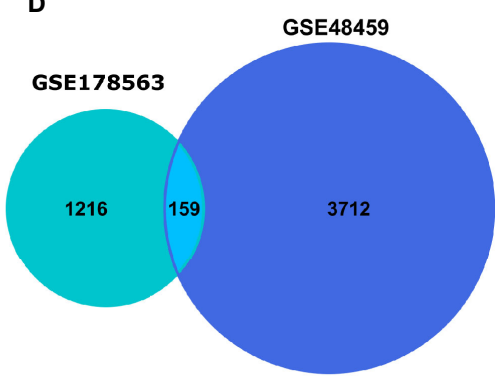

FIGURE 7 | Comparative transcriptomic analysis of GSE178563 (mite-infested human skin biopsies) with GSE48459 (live-mite-infested human skin equivalent group). (A, B) Correlation plot of logFC profiles and association statistics (contingency table and fisher's exact test) of significantly differentially expressed genes in mite-infested human skin biopsies and in-vitro human skin equivalents. (C, D) Venn diagram of common significantly upregulated and downregulated genes. Significantly enriched pathways in the shared profiles are mentioned.

Differentially expressed genes that were enhanced in OS included immune-related signaling pathways and JAK-STAT pathways. Their impacts include activation of macrophages and neutrophils, host inflammatory responses, and the differentiation of $\mathrm{B}$ and $\mathrm{T}$ cells, which control the wound repair (67). The JAK-STAT signaling pathway has been noted in rabbits infested with $S$. scabiei, where it was differentially expressed at multiple time points, indicating the main signaling pathway of innate immune response $(23,68)$. JAK1 and JAK2 signaling pathways are involved in dysregulation in atopic dermatitis and asthma immune response and include Th2 response exaggeration, B-cell maturation, and activation of eosinophils. It is crucial in atopic dermatitis pathogenesis with upregulation of epidermal chemokines and pro-inflammatory cytokines and downregulation of antimicrobial peptides. Thus, it plays a key role in the pathogenesis of immune-mediated disease and design of novel therapeutic approaches in the treatment of immune disorders $(69,70)$.

\section{Upregulated Genes for Keratinization}

Keratinocyte dermal cells has been reported to modulate the secretion of cytokines and expression of cell adhesion molecules in response to scabies mite infestation (24). The top six upregulated genes for keratinization in OS include KRT6C, which is also reported to be highly upregulated gene in psoriatic skin $(59,71,72)$, and KRT9 gene, a mutation that is responsible for the most common form of autosomal dominant Palmoplantar keratodermas (PPK) $(73,74)$. LCE3A gene is also associated with keratinization and was upregulated in OS. It is associated with cornification of the epidermis to become stratum corneum in human skin equivalents when exposed with scabies live mites (24), have defensin-like antimicrobial activity against a variety of bacterial taxa $(75,76)$, have role in skin repair, and reported to be upregulated in psoriasis $(77,78)$. The upregulated OS genes SPRR3 and SPRR2A are the encrypt for the Late Cornified Envelope (LCE) protein present in cornified cell envelope (CE) in both psoriasis and atopic dermatitis; the expression of these genes is linked to keratinocyte terminal differentiation both in vivo and in vitro (79).

Wnt signaling pathway is involved at the earliest stage of skin development as a dominant pathway controlling the patterning of the skin, cell proliferation, and maintaining homeostasis of the skin (80-82). The downregulation of Wnt signaling pathways has been observed in OS samples and corresponds to pathway analysis in psoriasis, which revealed downregulation of all members of the canonical Wnt signaling pathway (83). 


\section{Top Downregulated Genes}

Our results revealed that amongst the top downregulated genes, the antigen recognition and binding of immunoglobulin genes (IGLV6-57, IGHV3-30, IGLV4-69, IGHEP1) and T-cell receptor gene (TRBV13) in OS samples are similar to that reported previously (23). These genes were shown to be downregulated in the porcine model of CS at 2 and 8 weeks, where antigenpresenting cells are essential for $\mathrm{T}$ cell activation. Conversely, upregulation of immunoregulatory molecules in mite infestation may suppress the pathogenic inflammatory $\mathrm{T}$ cells, which contribute to skin pathology in OS.

AADACL3 gene, reported to be amplified in recurrent crusted scabies samples, was found among the most deregulated genes in our study. AADACL3 has duplicate regions on chromosome 1 (1p36) and belongs to a lipolytic enzyme family. Its significance in skin immunodeficiency is not still clear, but it has been reported that the duplicated regions contained more than 100 genes downregulated at the mRNA level in unaffected tissue (33).

Our results showed that the pathways associated with skin development, including keratinization, epidermis development, and keratinocyte differentiation, were highly upregulated in OS, which is also in accordance with previous findings (24). In addition, early immune-related responses along with cytokine activity, chemokine signaling pathways, monocyte chemotaxis, and CXCR (chemokine receptor binding) are also upregulated in scabies transcriptomic profiles. The immune component has previously been shown to be involved in scabies infestation (84), and particularly cytokines along with chemokines orchestrate this early immune response in scabies (35).

\section{Itch-Associated Genes of Mites}

The PLA2 family of group IV enzymes are involved in cell signaling and the inflammatory response via production of arachidonic acid, which is a precursor for eicosanoids. The eicosanoid subfamily of prostaglandins and leukotrienes is known to be involved in itch (85). Furthermore, TRPV1, which mediates histamine-induced itching via activation of PLA2, was significantly downregulated in scabies itch $(86,87)$. The k-opioid receptor gene (OPRK1) was upregulated, which may play a significant role in the propagation of chronic itch (88). Another promising target is HRH3, the gene for histamine receptor 3. This was found to be overexpressed in scabies miteinfested skin. It is involved in enhancement of antigenpresenting capacity of dendritic cells and TH1priming. H3Rs are also reported to have a role in treatment of some allergic and inflammatory conditions. H3R is also responsible for the allergic rhinitis symptoms, atopic dermatitis, and pruritus $(89,90)$. IL-4 and IL-31 were also significantly high in scabies mite-infested skin. IL-4 is reported to increase the itching even in low dose of histamine (91), and IL-31 is known to be involved in causing itching by signal activation of IL-13 receptors, but the mechanism involved is still unclear (92). Moreover, JAK1 signaling in sensory neurons also leads to chronic itching, and blocking of neurol JAK1 signaling can limit itching in noninflammatory situation (91).

\section{Comparative Analysis of Mite-Infested Human Skin Biopsies}

Comparative analysis between mite-infested human skin biopsies and E-MTAB6433 (crusted scabies vs. control; week 8) revealed a direct association between porcine crusted scabies $v s$. ordinary scabies (week 8) as well as for both pig groups (CS vs. OS and CS $v$ s. C; Week 8). The shared upregulated genes between mite-infested human skin biopsies and porcine database include chemokine ligands and receptors (CCL17, CCL18, CCL3L1, CCL3L3, CCR7), which play a crucial role in immune cell activation and stimulation of host inflammatory responses. CCL17 and CCL18 are chemokines that are significantly involved in T cell-mediated reactions and characteristic for various inflammatory skin diseases with TH2 dominance (93). CCL3L1 and CCL3L3 caused inflammatory cellular infiltrate in burrowing mites, and effector molecules are associated with salivary secretion and fecal material and reported to induce chemotactic response in the mite vicinity (24). Likewise, several chemokines, CCL3L1, CCL17, CXCL2, and selectin SELPLG, were upregulated at week 8 in CS and have been implicated in various inflammatory skin diseases. Whereas CXCL11 and CXCL16 are associated with chemotactic T-cell activation in skin and were downregulated at week 8 in CS (23).

The human skin equivalents study also showed upregulation of cutaneous T cell-attracting chemokine (CTACK, CCL27) and thymus- and activation-regulated cytokine (TARC, CCL17) in response to scabies mites (94). The reported list of inflammatory mediators found in atopic dermatitis includes S100A7, S100A8 S100A9, CCL2, CCL3, IL36A, IL36G, and IL36RN. These are involved in receptors triggering expression of myeloid cells TERM1 and skin barrier proteins and keratin 16 (95).

The cytokines IL-13 and IL-20 were also upregulated in all three groups studied in comparison analysis. IL-13 is known to drive antibody class switching and induce expression of $\operatorname{IgG}_{4}$ (96). It has been associated with Th2 type inflammation in scabies inflammatory and allergic responses (97), have a role in macrophage activation (98), and contribute to allergic inflammation in CS $(23,35)$. IL-20 is also a proinflammatory cytokine produced by keratinocytes, monocytes, and endothelial cells and is associated with epidermal thickening, scales, and crusts in CS $(19,99)$. The analysis of KEGG pathway at week 8 showed upregulation of JAK-STAT signaling pathway, as reported previously, and in the CS vs. C and CS vs. OS commonly upregulated groups (46).

Our transcriptomic data analysis of mite-infested human skin biopsies in OS $v s$. C revealed genes with pathophysiology of inflammatory disorders as seen in psoriasis and atopic dermatitis. The result has provided a significant insight into inflammatory and susceptible immune disorders responsible in scabies and the role of these chemokines, cytokines, and certain other molecules and related pathways in scabies clinical manifestations. Our study has provided an insight into cytokine-mediated signaling pathways and signal transduction. These include genes involved in immune cell activation and recruitment in OS, including DEFB4A and IL-19 induced by IL-17A, which cause upregulation of Th2 cytokines in allergic patients. IL-19 may also be applicable as an assessment tool in scabies, 
as suggested for psoriasis and atopic dermatitis patients. SERPINB4 genes play a role in inflammatory responses and control the important innate immune responses involving inflammation and complement cascade. The differentially expressed genes of OS are immune-related signaling pathways enriched in JAK-STAT pathways, which impact activation of macrophages and neutrophils, host inflammatory responses, and regulate the differentiation of $\mathrm{B}$ and $\mathrm{T}$ cells. IL-17 is a promising immunotherapeutic target and could be a promising therapy for the treatment of OS, in combination with acaricides. Immune-based therapies are currently in clinical trials for various inflammatory diseases, and efficacy has been seen in clinical trials in psoriasis.

The detailed transcriptomic profile has provided an insight into molecular functions, biological processes, and immunological responses. It has increased our understanding about overall gene expression in scabies in human, identified the crucial underlying biological process involved in scabies pathology and physiology, and identified immunotherapy targets for scabies.

\section{DATA AVAILABILITY STATEMENT}

The data set of this research work have been deposited in NCBI's Gene Expression Omnibus and are accessible through GEO Series accession number GSE178563 (https://www.ncbi.nlm. nih.gov/geo/query/acc.cgi?acc=GSE178563).

\section{ETHICS STATEMENT}

Ethical approval for the collection of human skin biopsies was granted by the Chairman, Institutional Review Board, and Ethics Committee of the National University of Medical Sciences (NUMS), Rawalpindi, Pakistan, after compliance with the observations of the two reviewers, under letter No. NUMS/P (VC) - 17/R\&D/ORIC/IRB\&EC approved on November 9, 2017. The patients/participants provided their written informed consent to participate in this study.

\section{AUTHOR CONTRIBUTIONS}

SN and SW conceived, designed, and wrote and reviewed the project and manuscript. HS, SI, and AF conducted the analysis and also wrote part of the manuscript. WH provided the technical

\section{REFERENCES}

1. Pence DB, Ueckermann E. Sarcoptic Manage in Wildlife. Rev Scientifique Technique (International Office Epizootics) (2002) 21:385-98. doi: 10.20506/ rst.21.2.1335

2. Walton SF, Currie BJ. Problems in Diagnosing Scabies, a Global Disease in Human and Animal Populations. Clin Microbiol Rev (2007) 20:268-79. doi: 10.1128/CMR.00042-06

3. Holt DC, Burgess ST, Reynolds SL, Mahmood W, Fischer K. Intestinal Proteases of Free-Living and Parasitic Astigmatid Mites. Cell Tissue Res (2013) 351:339-52. doi: 10.1007/s00441-012-1369-9 facilities and helped in analysis. ZS provided the samples and data for the study. All authors contributed to the article and approved the submitted version.

\section{FUNDING}

The project is funded by Higher Education Commission (HEC), Pakistan, under Startup Research Grant Program (SRGP) to SN (SRGP \# 1640). The funders had no role in study design, data collection and analysis, decision to publish or preparation of the manuscript.

\section{ACKNOWLEDGMENTS}

We are thankful to Dr. Aisha Mohyuddin of Department of Biological Sciences, National University of Medical Sciences (NUMS), Rawalpindi, Pakistan, for intellectual support and assistance in the work.

\section{SUPPLEMENTARY MATERIAL}

The Supplementary Material for this article can be found online at: https://www.frontiersin.org/articles/10.3389/fimmu.2021. 778840/full\#supplementary-material

Supplementary Table 1 | Clinical and demographic profile of human skin biopsy samples in GSE178563.

Supplementary Table 2 | Number of RNA-seq reads per sample.

Supplementary Table 3 | Association analysis (contingency tables, odds ratio, and fisher's exact test) of mite-infested human scabies with 15 different porcine groups.

Supplementary Table 4 | DEGs in porcine group (CS vs. C; Week 8) and matched differential expressed results from mite-infested human dataset.

Supplementary Table 5 | DEGs in porcine group (CS vs. OS; Week 8) and matched differential expressed results from mite-infested human dataset.

Supplementary Table 6 | Complete differential expression profile from miteinfested human skin equivalents (GSE48456) and human skin biopsies (GSE178563)

Supplementary Figure 1 | RNA integrity $(\mathrm{RIN})$ values of eight samples used for RNA sequencing.

4. Engelman D, Kiang K, Chosidow O, McCarthy J, Fuller C, Lammie P, et al Toward the Global Control of Human Scabies: Introducing the International Alliance for the Control of Scabies. PloS Negl Trop Dis (2013) 8:e2167. doi: 10.1371/journal.pntd.0002167

5. Andrews RM, McCarthy J, Carapetis JR, Currie BJ. Skin Disorders, Including Pyoderma, Scabies, and Tinea Infections. Pediatr Clin (2009) 56:1421-40. doi: 10.1016/j.pcl.2009.09.002

6. Walton SF, Beroukas D, Roberts-Thomson P, Currie BJ. New Insights Into Disease Pathogenesis in Crusted (Norwegian) Scabies: The Skin Immune Response in Crusted Scabies. Br J Dermato (2008) 158:1247-55. doi: 10.1111/ j.1365-2133.2008.08541 
7. Stemmer BL, Arlian LG, Morgan MS, Rapp CM, Moore PF. Characterization of Antigen Presenting Cells and T-Cells in Progressing Scabietic Skin Lesions. Vet Parasitol (1996) 67:247-58. doi: 10.1016/s0304-4017(96)01038-2

8. Arlian LG, Rapp CM, Vyszenskimoher DL, Morgan MS. Sarcoptes Scabiei: Histopathological Changes Associated With Acquisition and Expression of Host Immunity to Scabies. Exp Parasitol (1994) 78:51-63. doi: 10.1006/ expr.1994.1005

9. Arlian LG, Morgan MS, Neal JS. Modulation of Cytokine Expression in Human Keratinocytes and Fibroblasts by Extracts of Scabies Mites. Am J Trop Med Hyg (2003) 69:652-6. doi: 10.4269/ajtmh.2003.69.652

10. Cadman ET, Lawrence RA. Granulocytes: Effector Cells or Immunomodulators in the Immune Response to Helminth Infection? Parasit Immunol (2010) 32:1-9. doi: 10.1111/j.1365-3024.2009.01147.x

11. Crivellato E, Travan L, Ribatti D. Mast Cells and Basophils: A Potential Link in Promoting Angiogenesis During Allergic Inflammation. Int Arch Allergy Immunol (2010) 151:89-97. doi: 10.1159/000235998

12. Cabrera R, Agar A, Dahl MV. The Immunology of Scabies. Semin Dermatol (1993) 12(15-21).

13. Arlian LG, Rapp CM, Stemmer BL, Morgan MS, Moore PF. Characterization of Lymphocyte Subtypes in Scabietic Skin Lesions of Naive and Sensitized Dogs. Vet Parasitol (1997) 68:347-58. doi: 10.1016/s0304-4017(96)01093-x

14. Akdis M, Trautmann A, Klunker S, Blaser K, Akdis CA. Cytokine Network and Dysregulated Apoptosis in Atopic Dermatitis. Acta Odontol Scand (2001) 59:178-82. doi: 10.1080/000163501750266783

15. Bandi KM, Saikumar C. Sarcoptic Mange: A Zoonotic Ectoparasitic Skin Disease. J Clin Diagn Res (2013) 7:156. doi: 10.7860/JCDR/2012/4839.2694

16. Casais R, Granda V, Balseiro A, Del Cerro A, Dalton KP, González R, et al. Vaccination of Rabbits With Immunodominant Antigens From Sarcoptes Scabiei Induced High Levels of Humoral Responses and Pro-Inflammatory Cytokines But Confers Limited Protection. Parasit Vectors (2016) 9:1-3. doi: 10.1186/s13071-016-1717-9

17. Roberts LJ, Huffam SE, Walton SF, Currie BJ. Crusted Scabies: Clinical and Immunological Findings in Seventy-Eight Patients and a Review of the Literature. J Infect (2005) 50:375-81. doi: 10.1016/j.jinf.2004.08.033

18. Lalli PN, Morgan MS, Arlian LG. Skewed Th1/Th2 Immune Response to Sarcoptes Scabiei. J Parasitol (2004) 90:711-4. doi: 10.1645/GE-214R

19. Walton SF, Pizzutto S, Slender A, Viberg L, Holt D, Hales BJ, et al. Increased Allergic Immune Response to Sarcoptes Scabiei Antigens in Crusted Versus Ordinary Scabies. Clin Vaccine Immunol (2010) 17:1428-38. doi: 10.1128/ CVI.00195-10

20. Gowda D, Wu X. Parasite Recognition and Signaling Mechanisms in Innate Immune Responses to Malaria. Front Immunol (2018) 9:3006. doi: 10.3389/ fimmu.2018.03006

21. Burgess ST, Frew D, Nunn F, Watkins CA, McNeilly TN, Nisbet AJ, et al. Transcriptomic Analysis of the Temporal Host Response to Skin Infestation With the Ectoparasitic Mite Psoroptes Ovis. BMC Genomics (2010) 11:1-28. doi: 10.1186/1471-2164-11-624

22. Burgess ST, McNeilly TN, Watkins CA, Nisbet AJ, Huntley JF. Host Transcription Factors in the Immediate Pro-Inflammatory Response to the Parasitic Mite Psoroptes Ovis. PloS One (2011) 6:e24402. doi: 10.1371/ journal.pone.0024402

23. Bhat SA, Walton SF, Ventura T, Liu X, McCarthy JS, Burgess ST, et al. Early Immune Suppression Leads to Uncontrolled Mite Proliferation and Potent Host Inflammatory Responses in a Porcine Model of Crusted Versus Ordinary Scabies. PloS Negl Trop Dis (2020) 14:e0008601. doi: 10.1371/journal. pntd.0008601

24. Morgan MS, Arlian LG, Markey MP. Sarcoptes Scabiei Mites Modulate Gene Expression in Human Skin Equivalents. PloS One (2013) 8:e71143. doi: 10.1371/journal.pone.0071143

25. Li H, Durbin R. Fast and Accurate Short Read Alignment With BurrowsWheeler Transform. Bioinformatics (2009) 25:1754-60. doi: 10.1093/ bioinformatics/btp324

26. Anders S, Pyl PT, Huber W. HTSeq-a Python Framework to Work With High-Throughput Sequencing Data. Bioinformatics (2015) 31:166-9. doi: 10.1093/bioinformatics/btu638

27. Chng L, Holt DC, Field M, Francis JR, Tilakaratne D, Dekkers MH, et al. Molecular Diagnosis of Scabies Using a Novel Probe-Based Polymerase Chain Reaction Assay Targeting High-Copy Number Repetitive Sequences in the
Sarcoptes Scabiei Genome. PloS Negl Trop Dis (2021) 15:e0009149. doi: 10.1371/journal.pntd.0009149

28. Sherman BT, Tan Q, Collins JR, Alvord WG, Roayaei J, Stephens R, et al. The DAVID Gene Functional Classification Tool: A Novel Biological ModuleCentric Algorithm to Functionally Analyze Large Gene Lists. Genome Biol (2007) 8:1-6. doi: 10.1186/gb-2007-8-9-r183

29. Jiao X, Sherman BT, Huang DW, Stephens R, Baseler MW, Lane HC, et al. DAVID-WS: A Stateful Web Service to Facilitate Gene/Protein List Analysis. Bioinformatics (2012) 28:1805-6. doi: 10.1093/bioinformatics/bts251

30. Subramanian A, Tamayo P, Mootha VK, Mukherjee S, Ebert BL, Gillette MA, et al. Gene Set Enrichment Analysis: A Knowledge-Based Approach for Interpreting Genome-Wide Expression Profiles. PNAS (2005) 102:15545-50. doi: 10.1073/pnas.0506580102

31. Smith ML, Durinck S, Huber W. Accessing Ensembl Annotation With biomaRt. (2021).

32. Ritchie ME, Phipson B, Wu DI, Hu Y, Law CW, Shi W, et al. Limma Powers Differential Expression Analyses for RNA-Sequencing and Microarray Studies. Nucleic Acids Res (2015) 43:e47. doi: 10.1093/nar/gkv007

33. Hatter AD, Soler DC, Curtis C, Cooper KD, McCormick TS. Case Report of Individual With Cutaneous Immunodeficiency and Novel 1p36 Duplication. Appl Clin Genet (2016) 9:1. doi: 10.2147/TACG.S90713

34. Arlian LG, Platts-Mills TA. The Biology of Dust Mites and the Remediation of Mite Allergens in Allergic Disease. J Allergy Clin Immunol (2001) 107:S406413. doi: $10.1067 /$ mai.2001.113670

35. Bhat SA, Mounsey KE, Liu X, Walton SF. Host Immune Responses to the Itch Mite, Sarcoptes Scabiei, in Humans. Parasit Vectors (2017) 10:1-2. doi: 10.1186/s13071-017-2320-4

36. Krueger JG, Wharton KA Jr, Schlitt T, Suprun M, Torene RI, Jiang X, et al. IL17A Inhibition by Secukinumab Induces Early Clinical, Histopathologic, and Molecular Resolution of Psoriasis. J Allergy Clin Immunol (2019) 144:750-63. doi: 10.1016/j.jaci.2019.04.029

37. Lowes MA, Russell CB, Martin DA, Towne JE, Krueger JG. The IL-23/T17 Pathogenic Axis in Psoriasis Is Amplified by Keratinocyte Responses. Trends Immunol (2013) 34:174-81. doi: 10.1016/j.it.2012.11.005

38. Chiricozzi A, Suárez-Fariñas M, Fuentes-Duculan J, Cueto I, Li K, Tian S, et al. Increased Expression of Interleukin-17 Pathway Genes in Nonlesional Skin of Moderate-to-Severe Psoriasis Vulgaris. Br J Dermatol (2016) 174:136-45. doi: 10.1111/bjd.14034

39. Kolbinger F, Loesche C, Valentin MA, Jiang X, Cheng $\mathrm{Y}$, Jarvis $\mathrm{P}$, et al. $\beta$-Defensin 2 Is a Responsive Biomarker of IL-17A-Driven Skin Pathology in Patients With Psoriasis. J Allergy Clin Immunol (2017) 139:923-32. doi: 10.1016/j.jaci.2016.06.038

40. Borchers NS, Santos-Valente E, Toncheva AA, Wehkamp J, Franke A, Gaertner VD, et al. Human $\beta$-Defensin 2 Mutations Are Associated With Asthma and Atopy in Children and Its Application Prevents Atopic Asthma in a Mouse Model. Front Immunol (2021) 12:636061. doi: 10.3389/ fimmu.2021.636061

41. Rutz S, Wang X, Ouyang W. The IL-20 Subfamily of Cytokines-From Host Defense to Tissue Homeostasis. Nat Rev Immunol (2014) 14:783-95. doi: $10.1038 /$ nri3766

42. Liao SC, Cheng YC, Wang YC, Wang CW, Yang SM, Yu CK, et al. IL-19 Induced Th2 Cytokines and was Up-Regulated in Asthma Patients. J Immunol Res (2004) 173:6712-8. doi: 10.4049/jimmunol.173.11.6712

43. Konrad RJ, Higgs RE, Rodgers GH, Ming W, Qian YW, Bivi N, et al. Assessment and Clinical Relevance of Serum IL-19 Levels in Psoriasis and Atopic Dermatitis Using a Sensitive and Specific Novel Immunoassay. Sci Rep (2019) 9(1):1-5. doi: 10.1038/s41598-019-41609-z

44. Witte E, Kokolakis G, Witte K, Philipp S, Doecke WD, Babel N, et al. IL-19 Is a Component of the Pathogenetic IL-23/IL-17 Cascade in Psoriasis. J Invest Dermatol (2014) 134:2757-67. doi: 10.1038/jid.2014.308

45. Russo RC, Garcia CC, Teixeira MM, Amaral FA. The CXCL8/IL-8 Chemokine Family and Its Receptors in Inflammatory Diseases. Expert Rev Clin Immunol (2014) 10:593-619. doi: 10.1586/1744666X.2014.894886

46. Ha H, Debnath B, Neamati N. Role of the CXCL8-CXCR1/2 Axis in Cancer and Inflammatory Diseases. Theranostics (2017) 7:1543. doi: 10.7150/ thno. 15625

47. Nedoszytko B, Sokołowska-Wojdyło M, Ruckemann-Dziurdzińska K, Roszkiewicz J, Nowicki RJ. Chemokines and Cytokines Network in the 
Pathogenesis of the Inflammatory Skin Diseases: Atopic Dermatitis, Psoriasis and Skin Mastocytosis. Postepy Dermatol i Alergol (2014) 31:84-91. doi: 10.5114/pdia.2014.40920

48. Duan H, Koga T, Kohda F, Hara H, Urabe K, Furue M. Interleukin-8-Positive Neutrophils in Psoriasis. J Dermatol Sci (2001) 26:119-24. doi: 10.1016/s09231811(00)00167-5

49. Barrett NA, Austen KF. Innate Cells and T Helper 2 Cell Immunity in Airway Inflammation. Immunity (2009) 31:425-37. doi: 10.1016/j.immuni. 2009.08.014

50. Hahn J, Knopf J, Maueroder C, Kienhofer D, Leppkes M, Herrmann M. Neutrophils and Neutrophil Extracellular Traps Orchestrate Initiation and Resolution of Inflammation. Clin Exp Rheumatol (2016) 34:6-8.

51. Luo DQ, Huang MX, Liu JH, Tang W, Zhao YK, Sarkar R. Bullous Scabies. Am J Trop Med Hyg (2016) 95:689-93. doi: 10.4269/ajtmh.16-0273

52. Dagleish MP, Ali Q, Powell RK, Butz D, Woodford MH. Fatal Sarcoptes Scabiei Infection of Blue Sheep (Pseudois Nayaur) in Pakistan. J Wildl Dis (2007) 43:512-7. doi: 10.7589/0090-3558-43.3.512

53. Eming SA, Koch M, Krieger A, Brachvogel B, Kreft S, Bruckner-Tuderman L, et al. Differential Proteomic Analysis Distinguishes Tissue Repair Biomarker Signatures in Wound Exudates Obtained From Normal Healing and Chronic Wounds. J Proteome Res (2010) 9:4758-66. doi: 10.1021/pr100456d

54. Sivaprasad U, Kinker KG, Ericksen MB, Lindsey M, Gibson AM, Bass SA, et al. SERPINB3/B4 Contributes to Early Inflammation and Barrier Dysfunction in an Experimental Murine Model of Atopic Dermatitis. J Investig Dermatol (2015) 135:160-9. doi: 10.1038/jid.2014.353

55. Chovatiya R, Silverberg JI. Pathophysiology of Atopic Dermatitis and Psoriasis: Implications for Management in Children. Children (2019) 6:108. doi: 10.3390/children6100108

56. Sinno H, Prakash S. Complements and the Wound Healing Cascade: An Updated Review. Plast Surg Int (2013) 146764:1-8. doi: 10.1155/2013/146764

57. Swe PM, Christian LD, Lu HC, Sriprakash KS, Fischer K. Complement Inhibition by Sarcoptes Scabiei Protects Streptococcus Pyogenes - An In Vitro Study to Unravel the Molecular Mechanisms Behind the Poorly Understood Predilection of S. Pyogenes to Infect Mite-Induced Skin Lesions. PloS Negl Trop Dis (2017) 11:e0005437. doi: 10.1371/journal.pntd. 0005437

58. Iversen OJ, Lysvand H, Slupphaug G. Pso P27, a SERPINB3/B4-Derived Protein, Is Most Likely a Common Autoantigen in Chronic Inflammatory Diseases. Clin Immunol (2017) 174:10-7. doi: 10.1016/j.clim.2016.11.006

59. Ahn R, Yan D, Chang HW, Lee K, Bhattarai S, Huang ZM, et al. RNA-Seq and Flow-Cytometry of Conventional, Scalp, and Palmoplantar Psoriasis Reveal Shared and Distinct Molecular Pathways. Sci Rep (2018) 8:1-2. doi: 10.1038/ s41598-018-29472-w

60. Renert-Yuval Y, Thyssen JP, Bissonnette R, Bieber T, Kabashima K, Hijnen D, et al. Biomarkers in Atopic Dermatitis-A Review on Behalf of the International Eczema Council. J Allergy Clin Immunol (2021) 28:1-6. doi: 10.1016/j.jaci.2021.01.013

61. Lembo S, Raimondo A. Polymorphic Light Eruption: What's New in Pathogenesis and Management. Front Med (2018) 5:252. doi: 10.3389/ fmed.2018.00252

62. Dainichi T, Hanakawa S, Kabashima K. Classification of Inflammatory Skin Diseases: A Proposal Based on the Disorders of the Three-Layered Defense Systems, Barrier, Innate Immunity and Acquired Immunity. J Dermatol Sci (2014) 76:81-9. doi: 10.1016/j.jdermsci.2014.08.010

63. Trzeciak M, Olszewska B, Sakowicz-Burkiewicz M, Sokołowska-Wojdyło M, Jankau J, Nowicki RJ, et al. Expression Profiles of Genes Encoding Cornified Envelope Proteins in Atopic Dermatitis and Cutaneous T-Cell Lymphomas. Nutrients (2020) 12:862. doi: 10.3390/nu12030862

64. Henry J, Hsu CY, Haftek M, Nachat R, de Koning HD, Gardinal-Galera I, et al. Hornerin Is a Component of the Epidermal Cornified Cell Envelopes. FASEB J (2011) 25:1567-76. doi: 10.1096/fj.10-168658

65. Martin MJ, Estravís M, García-Sánchez A, Dávila I, Isidoro-García M, Sanz C. Genetics and Epigenetics of Atopic Dermatitis: An Updated Systematic Review. Genes (2020) 11:442. doi: 10.3390/genes11040442

66. Garreis F, Jahn J, Wild K, Abrar DB, Schicht M, Schröder JM, et al. Expression and Regulation of S100 Fused-Type Protein Hornerin at the Ocular Surface and Lacrimal Apparatus. Invest Ophthalmol Vis Sci (2017) 58:5968-77. doi: $10.1167 /$ iovs.17-22637
67. Tanji T, Hu X, Weber AN, Ip YT. Toll and IMD Pathways Synergistically Activate an Innate Immune Response in Drosophila Melanogaster. Mol Cell Biol (2007) 27:4578-88. doi: 10.1128/MCB.01814-06

68. He R, Gu X, Lai W, Peng X, Yang G. Transcriptome-microRNA Analysis of Sarcoptes Scabiei and Host Immune Response. PloS One (2017) 12(5): e0177733. doi: 10.1371/journal.pone.0177733

69. Bao L, Zhang H, Chan LS. The Involvement of the JAK-STAT Signaling Pathway in Chronic Inflammatory Skin Disease Atopic Dermatitis. JAK-STAT (2013) 2:e24137. doi: 10.4161/jkst.24137

70. Seif F, Khoshmirsafa M, Aazami H, Mohsenzadegan M, Sedighi G, Bahar M. The Role of JAK-STAT Signaling Pathway and Its Regulators in the Fate of T Helper Cells. Cell Commun Signal (2017) 15:23. doi: 10.1186/s12964-017$0177-y$

71. Quaranta M, Knapp B, Garzorz N, Mattii M, Pullabhatla V, Pennino D, et al. Intraindividual Genome Expression Analysis Reveals a Specific Molecular Signature of Psoriasis and Eczema. Sci Transl Med (2014) 6(244):244ra90doi: 10.1126/scitranslmed.3008946

72. Chow M, Lai K, Ahn R, Gupta R, Arron S. Effect of Adalimumab on Gene Expression Profiles of Psoriatic Skin and Blood. J Drugs Dermatol (2016) 15:988.

73. Has C, Technau-Hafsi K. Palmoplantar Keratodermas: Clinical and Genetic Aspects. J Dtsch Dermatol Ges (2016) 14:123-40. doi: 10.1111/ddg.12930

74. Li C, Chen P, Sun S, Zeng K, Liang J, Wang Q, et al. Exome Sequencing Identifies a KRT9 Pathogenic Variant in a Chinese Pedigree With Epidermolytic Palmoplantar Keratoderma. Mol Genet Genomic Med (2019) 7:e00703. doi: $10.1002 / \mathrm{mgg} 3.703$

75. Archer NK, Dilolli MN, Miller LS. Pushing the Envelope in Psoriasis: Late Cornified Envelope Proteins Possess Antimicrobial Activity. J Investig Dermatol (2017) 137:2257-9. doi: 10.1016/j.jid.2017.08.026

76. Niehues H, Tsoi LC, van der Krieken DA, Jansen PA, Ortveld MA, RodijkOlthuis D, et al. Psoriasis-Associated Late Cornified Envelope (LCE) Proteins Have Antibacterial Activity. J Investig Dermatol (2017) 137:2380-8. doi: 10.1016/j.jid.2017.06.003

77. Bergboer JG, Tjabringa GS, Kamsteeg M, van Vlijmen-Willems IM, RodijkOlthuis D, Jansen PA, et al. Psoriasis Risk Genes of the Late Cornified Envelope-3 Group Are Distinctly Expressed Compared With Genes of Other LCE Groups. Am J Pathol (2011) 178:1470-7. doi: 10.1016/j.ajpath.2010.12.017

78. Chandra A, Lahiri A, Senapati S, Basu B, Ghosh S, Mukhopadhyay I, et al. Increased Risk of Psoriasis Due to Combined Effect of HLA-Cw6 and LCE3 Risk Alleles in Indian Population. Sci Rep (2016) 6:1-8. doi: 10.1038/ srep24059

79. Bowcock AM, Cookson WO. The Genetics of Psoriasis, Psoriatic Arthritis and Atopic Dermatitis. Hum Mol Genet (2004) 13(1):R43-55. doi: 10.1093/hmg/ ddh094

80. Lim X, Nusse R. Wnt Signaling in Skin Development, Homeostasis, and Disease. Cold Spring Harb Perspect Biol (2013) 5:1-25. doi: 10.1101/ cshperspect.a008029

81. Li J, Ji L, Chen J, Zhang W, Ye Z. Wnt/ß-Catenin Signaling Pathway in Skin Carcinogenesis and Therapy. BioMed Res Int (2015) 19:1-8. doi: 10.1155/ 2015/964842

82. Veltri A, Lang C, Lien WH. Concise Review: Wnt Signaling Pathways in Skin Development and Epidermal Stem Cells. Stem Cells (2018) 36:22-35. doi: $10.1002 /$ stem. 2723

83. Gudjonsson JE, Johnston A, Stoll SW, Riblett MB, Xing X, Kochkodan JJ, et al. Evidence for Altered Wnt Signaling in Psoriatic Skin. J Invest Dermatol (2010) 130:1849-59. doi: 10.1038/jid.2010.67

84. Swe PM, Fischer K. A Scabies Mite Serpin Interferes With ComplementMediated Neutrophil Functions and Promotes Staphylococcal Growth. PloS Negl Trop Dis (2014) 8:e2928. doi: 10.1371/journal.pntd.0002928

85. Neisius U, Olssonb R, Rukwied R, Lischetzki G, Schmelz M. Prostaglandin E2 Induces Vasodilation and Pruritus, But No Protein Extravasation in Atopic Dermatitis and Controls. J Am Acad Dermatol (2002) 47:28-32. doi: 10.1067/ mjd.2002.120462

86. Shim WS, Tak MH, Lee MH, Kim M, Kim M, Koo JY, et al. TRPV1 Mediates Histamine-Induced Itching via the Activation of Phospholipase A2 and 12Lipoxygenase. J Neurosci (2007) 27:2331-7. doi: 10.1523/JNEUROSCI

87. Nattkemper LA, Tey HL, Valdes-Rodriguez R, Lee H, Mollanazar NK, Albornoz C, et al. The Genetics of Chronic Itch: Gene Expression in the 
Skin of Patients With Atopic Dermatitis and Psoriasis With Severe Itch. J Invest Dermatol (2018) 138:1311-7. doi: 10.1016/j.jid.2017.12.029

88. Cowan A, Kehner GB, Inan S. Targeting Itch With Ligands Selective for $\kappa$ Opioid Receptors. Pharmacol Itch (2015) 226:291-314. doi: 10.1007/978-3662-44605-8_16

89. Tatarkiewicz J, Rzodkiewicz P, Żochowska M, Staniszewska A, BujalskaZadrożny M. New Antihistamines-Perspectives in the Treatment of Some Allergic and Inflammatory Disorders. Arch Med Sci (2019) 15:537. doi: 10.5114/aoms.2017.68534

90. Rossbach K, Nassenstein C, Gschwandtner M, Schnell D, Sander K, Seifert R, et al. Histamine H1, H3 and H4 Receptors Are Involved in Pruritus. Neuroscience (2011) 190:89-102. doi: 10.1016/j.neuroscience.2011.06.002

91. Oetjen LK, Mack MR, Feng J, Whelan TM, Niu H, Guo CJ, et al. Sensory Neurons Co-Opt Classical Immune Signaling Pathways to Mediate Chronic Itch. Cell (2017) 171:217-28. doi: 10.1016/j.cell.2017.08.006

92. Takamori A, Nambu A, Sato K, Yamaguchi S, Matsuda K, Numata T, et al. IL31 Is Crucial for Induction of Pruritus, But Not Inflammation, in Contact Hypersensitivity. Sci Rep (2018) 8(1):1-1. doi: 10.1038/s41598-018-25094-4

93. Morgan MS, Arlian LG. Response of Human Skin Equivalents to Sarcoptes Scabiei. J Med Entomol (2010) 47:877-83. doi: 10.1603/me10012

94. Arlian LG, Morgan MS, Neal JS. Extracts of Scabies Mites (Sarcoptidae: Sarcoptes Scabiei) Modulate Cytokine Expression by Human Peripheral Blood Mononuclear Cells and Dendritic Cells. J Med Entomol (2004) 41(1):69-73. doi: 10.1603/0022-2585-41.1.69

95. Suárez-Fariñas M, Ungar B, Correa da Rosa J, Ewald DA, Rozenblit M, Gonzalez J, et al. RNA Sequencing Atopic Dermatitis Transcriptome Profiling Provides Insights Into Novel Disease Mechanisms With Potential Therapeutic Implications. J Allergy Clin Immunol (2015) 135:1218-27. doi: 10.1016/j.jaci.2015.03.003
96. Collins AM, Jackson KJ. A Temporal Model of Human IgE and IgG Antibody Function. Front Immunol (2013) 4:235. doi: 10.3389/fimmu.2013.00235

97. Schroeder JT. Basophils: Emerging Roles in the Pathogenesis of Allergic Disease. Immunol Rev (2011) 242:144-60. doi: 10.1111/j.1600-065X. 2011.01023.x

98. Brombacher F. The Role of Interleukin-13 in Infectious Diseases and Allergy. BioEssays (2000) 22:646-56. doi: 10.1002/1521-1878(200007

99. Sabat R, Philipp S, Hoflich C, Kreutzer S, Wallace E, Asadullah K, et al. Immunopathogenesis of Psoriasis. Exp Dermatol (2007) 16:779-98. doi: 10.1111/j.1600-0625.2007.00629.x

Conflict of Interest: The authors declare that the research was conducted in the absence of any commercial or financial relationships that could be construed as a potential conflict of interest.

Publisher's Note: All claims expressed in this article are solely those of the authors and do not necessarily represent those of their affiliated organizations, or those of the publisher, the editors and the reviewers. Any product that may be evaluated in this article, or claim that may be made by its manufacturer, is not guaranteed or endorsed by the publisher.

Copyright (c) 2021 Shehwana, Ijaz, Fatima, Walton, Sheikh, Haider and Naz. This is an open-access article distributed under the terms of the Creative Commons Attribution License (CC BY). The use, distribution or reproduction in other forums is permitted, provided the original author(s) and the copyright owner(s) are credited and that the original publication in this journal is cited, in accordance with accepted academic practice. No use, distribution or reproduction is permitted which does not comply with these terms. 